\title{
Rotas seculares e monastérios talhados na rocha: a retórica da paisagem sagrada budista na costa oeste da Índia Antiga
}

\author{
Cibele Elisa Viegas Aldrovandi*
}

\begin{abstract}
ALDROVANDI, C.E.V. Rotas seculares e monastérios talhados na rocha: a retórica da paisagem sagrada budista na costa oeste da Índia Antiga. Revista do Museu de Arqueologia e Etnologia, São Paulo, 17: 39-67, 2007.
\end{abstract}

Resumo: $\mathrm{O}$ artigo discute, a partir do levantamento de campo realizado entre 2004 e 2005, o desenvolvimento e interação da paisagem sagrada budista na região do Deccan e Konkan. Centenas de grutas talhadas na rocha se desenvolveram ao longo das antigas rotas comerciais que interligavam a costa oeste do estado de Maharashtra, elas funcionam como marcos espaciais na paisagem permitindo determinar essas vias de acesso entre o litoral e o planalto. $O$ crescimento ininterrupto e recorrência desses conjuntos monásticos ao longo de um milênio são trabalhados a partir de uma perspectiva da retórica da paisagem sagrada. Essa abordagem possibilita compreender a interação e a dinâmica que permeou as esferas política, econômica e religiosa budista nessa área geográfica da Índia Antiga.

Palavras-chave: Retórica da Paisagem - Grutas budistas - Política Economia - Índia Antiga.

\section{Introdução}

T $\mathrm{m}$ antigo relato sobre o estado de Maharashtra, na costa oeste da Índia, foi preservado nos registros do monge chinês Hiuen Tsang, realizado no século VII d.C., durante sua peregrinação de aproximadamente duas décadas pelo subcontinente. Interessantes aspectos da política, economia, sociedade e do Budismo do período ficaram preservados nesse breve excerto apresentado a seguir:

(*) Pós-Doutorado pelo Museu de Arqueologia e Etnologia da Universidade de São Paulo. aldrovan@yahoo.com
This country is about 5000 li in circuit. The capital of Mo-ho-la-ch'a (Maharashtra) borders on the west on a great river. It is about 30 li round. The soil is rich and fertile; it is regularly cultivated and very productive (...). The king in consequence of his possessing these men and elephants, treats his neighbours with contempt. He is of the Kshattriya caste, and his name is Pulakesi. His plans and understandings are widespread, and his beneficent actions are felt over a great distance (...). The men are fond of learning and study both heretical and orthodox (books). There are about 100 sangharamas, with 5000 or so priests. They practice both the Great and Small 
Vehicle. There are about 100 Deva temples, in which very many heretics of different persuasions dwell. Within and without the capital are five stupas to mark the spots where the four past Buddhas walked and sat. They were built by Asoka-raja. There are, besides these, other stupas made of brick or stone, so many that it would be dificult to name them all (...). On the eastern frontier of the country is a great mountain with towering crags and a continuous stretch of piled-up rocks and scarped precipice. In this there is a sangharama constructed, in a dark valley. Its lofty halls and deep side-aisles open into the face of the rocks. Storey above storey they are backed by the crag and face the valley.

\section{Hiuen Thsiang [Si-Yu-Ki, XI.3 $]^{1}$}

Incrustadas nas colinas e escarpas rochosas que se erguem entre o litoral do Konkan e o planalto do Deccan, encontram-se as centenas de monastérios budistas talhados na rocha do estado de Maharashtra. Desde o final do século XIX, os pesquisadores haviam percebido que esses marcos espaciais de caráter religioso estiveram diretamente associados às rotas comerciais que interligavam essas duas áreas geográficas na antiguidade (Abbott 1891:121; Kosambi 1955:51-52; Dehejia, 1972:30-31).

No entanto, a maior parte dos estudos sobre essa paisagem sagrada budista, inaugurados por Fergusson e Burgess (1880) e realizados até o presente, focou-se em aspectos arquitetônicos e estilísticos, geralmente com objetivos descritivos e cronológicos, ou priorizou apenas uma das esferas que favoreceram o surgimento dos conjuntos monásticos, como a religião, a economia ou a política da região, em detrimento das demais. Assim, na presente discussão, a análise desse patrimônio

(1) Tradução de S. Beal. Si-Yu-Ki: Buddhist Records of the Western World, Chinese Accounts of India by Hiuen Thsiang (624-645 d.C.), 4 vols. (London, 1884), Delhi: Bharatiya Pub. House, 1980: 449-450. Transliteração original mantida. arquitetônico sagrado de características regionais únicas e cujo desenvolvimento ocorreu de modo ininterrupto ao longo de aproximadamente um milênio, foi conjugada aos demais aspectos econômicos e políticos que permearam sua história. Sob a perspectiva do que chamamos a retórica da paisagem sagrada (ver Duncan 1990:24) buscamos compreender a forma como a distribuição espacial e recorrência nos eixos sincrônico e diacrônico desses conjuntos monásticos refletem a interação e a dinâmica das esferas política, econômica e religiosa dessa área geográfica.

\section{$1.1 \mathrm{O}$ contexto geográfico}

As regiões do Konkan e Deccan, que compõem a porção oeste do estado de Maharashtra, pertencem a relevos geográficos distintos. A faixa litorânea e o planalto são interligados pela cadeia montanhosa Sahyadri que é intersectada perpendicularmente por formações escarpadas e paralelas. A faixa costeira do Konkan é composta pelos distritos de Thana ao norte, Kolaba no centro e Ratnagiri ao sul, cuja extensão, em direção ao planalto, pode variar entre 40 e $80 \mathrm{~km}$. Sua superfície irregular é caracterizada por platôs baixos de laterita, planícies associadas aos estuários de rios, cadeias e montanhas isoladas de elevação moderada. A costa alterna baías e promontórios que formam enseadas naturais. A região recebe fortes chuvas sazonais provindas das monções de sudoeste, principalmente entre os meses de junho a outubro. No restante do ano prevalece o clima quente e úmido. Os rios fluem para o oeste, provindos da cadeia Sahyadri e deságuam no Mar Arábico. O norte do Konkan possui uma extensão maior de superfície plana, formada por mangues e solo aluvial. A região central, ao sul de Panvel, é composta por montanhas baixas e transversais que terminam na linha costeira, bem como rios sazonais que fluem até estuários formados pelo assoreamento. A região sul do Konkan, abaixo de Ratnagiri, é uma faixa estreita de terra, com índice pluviométrico anual elevado (ver Nagaraju 1981:10-11).

A cadeia Sahyadri possui uma orientação norte-sul que tem início no vale de Novapur, 
perpassa a porção oeste de Nasik, Pune, Satara, Sangli, Kolhapur e segue para o estado de Karnataka. A altura média dessa formação rochosa fica acima dos $900 \mathrm{~m}$. Serras e estreitos numerosos fazem a ligação entre a faixa litorânea do Konkan e o planalto do Deccan. A porção oeste dessa cadeia montanhosa possui alto índice pluviométrico que diminui em direção a leste. O clima quente e úmido, da faixa oeste, permite a preservação de áreas de floresta com vegetação densa. A faixa leste, mais seca e com vales mais amplos, apresenta vegetação rasteira, seus rios correm em direção ao leste ou sudoeste e formam vastos cinturões de irrigação pontilhados por montanhas isoladas.

A topografia da região é formada, em sua maior parte, por rocha de origem vulcânica. A cadeia Sahyadri (Fig. 1), resultante do movimento tectônico - diastrofismo -, apresenta aspecto escarpado e intercalado por plataformas horizontais que dão a essas montanhas e vales uma aparência de amplos degraus ou terraços. Os picos montanhosos possuem forma de domo, os platôs e as bases planas estão associados a deposições sucessivas de camadas horizontais de magma vulcânico. Os vales dos rios foram formados pela erosão posterior. Esses depósitos geológicos contínuos, de natureza vulcânica, costumam apresentar uma mudança de padrão na densidade e estrutura da composição da rocha ígnea, decorrente do resfriamento lento do magma fundido, que resulta em estratos horizontais alternados de maior ou menor dureza.

A distribuição dos conjuntos de grutas escavadas na rocha e das rotas comerciais está diretamente associada à presença dessa topografia singular na costa oeste indiana. A cadeia montanhosa Sahyadri funcionava como uma barreira natural que dificultava o contato entre os portos do litoral do Konkan e as cidades do platô do Deccan. Assim, as passagens, estreitos e vales que ali existiam foram utilizados como rotas de acesso para interligar as duas áreas geográficas.

As regiões do norte do Konkan, distritos de Thana e Kolaba, e a área adjacente do Mawal, porção oeste do distrito de Pune, possuíam elementos mais favoráveis à ocupação humana - recursos hídricos, terras cultiváveis e florestas - e, mesmo na época atual, são as áreas mais populosas de Maharashtra.

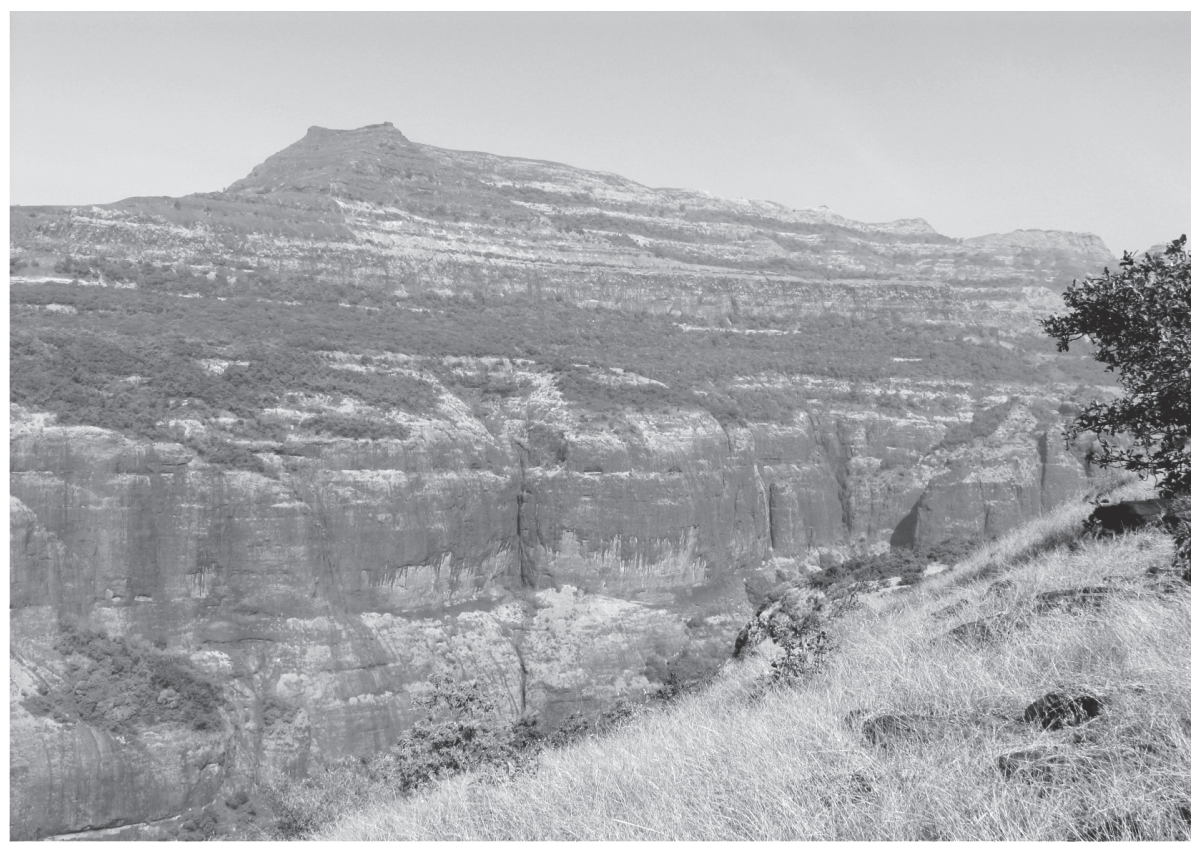

Fig. 1. Cadeia montanhosa Sahyadri com as escarpas rochosas de origem vulcânica (Aldrovandi 2004). 


\subsection{As grutas budistas talhadas na rocha}

O estado de Maharashtra, na costa oeste indiana, abriga o maior número de grutas talhadas na rocha de toda a Índia antiga, que, segundo estimativas, somam mais de $80 \%$ do total existente em todo o subcontinente. A maior parte desses conjuntos de grutas foi dedicada ao Budismo, mas também existem exemplos consagrados às demais religiões do Sul da Ásia. Segundo estimativas, existem em toda a Índia aproximadamente 1200 estruturas sagradas escavadas em rocha - entre elas, cerca de 100 seriam bramânicas, 900 budistas e as 200 restantes, jainistas (Coomaraswamy 1965:97; Chakrabarti 1995:199). Esta análise esteve centrada especificamente nos conjuntos monásticos associados ao Budismo.

Durante o estágio de pesquisa desenvolvido no Deccan College Post-Graduate and Research Institute, em Pune, além da escavação do sítio arqueológico de Chaul (ver Gogte e Aldrovandi 2005-2006), foi realizado um levantamento sistemático dos conjuntos monásticos budistas existentes no estado de Maharashtra (Aldrovandi 2006:508-592). O próprio sítio portuário de Chaul fez parte da intrincada rede econômicoreligiosa que existiu nessa área geográfica, como ficou atestado pelos vestígios arqueológicos ali escavados e pelos conjuntos de grutas budistas associados.

A etapa de exploração e levantamento fotográfico das grutas talhadas na rocha abrangeu os conjuntos monásticos de Kuda (N 18¹7'10.4"; EO 73॰04'21.1"), Mahad (N 18०05'13.2"; EO 73०24'15.2"), Gomasi (N 18॰27'57.6"; EO 73॰17'53.4"), Bhaja (N 1843'46.2"EO 73०28'52.5"), Karli (N 18॰47'00.5"; EO 73॰28'13.4"), Kanheri (N 19॰12’30.1"; EO 72॰54'18.2"), Kondivite (N 19०09'17.2"; EO 72॰53'28.2"), Ajanta (N 20.33'05.9"; EO 75॰41'56.4"), Ellora (N 20॰01'11.5"; EO 75¹0'42.1") e os três grupos de Chaul, anteriormente citados. A seleção das grutas baseou-se em fatores como: distância entre os sítios, condições de acesso, tempo necessário para o levantamento, diversidade formal e temporal, bem como representatividade das categorias arquitetônicas e iconográficas existentes (Fig. 2).
Assim como o Budismo, os primórdios da arquitetura budista tiveram origem na região do Vale do Ganges e remontam aos primeiros séculos a.C., durante o final da era Maurya. Os exemplares mais antigos de grutas talhadas na rocha de que se tem conhecimento ficam nas montanhas Barabar e Nagarjuni, no estado de Bihar, no norte da Índia. Entre elas, a gruta de Lomash Rsi, datada do século III a.C. da era de Ashoka, é a mais conhecida (ver Huntington 1985:48-50). A fase de maior complexidade no desenvolvimento dos conjuntos monásticos do Deccan e Konkan é contemporânea às tradições das escolas de Gandhara e Mathura, no noroeste e norte da Índia, que se encontrava sob a égide Kushan. Essa tradição construtiva apresentou continuidade até o início do período Rastrakuta, no século VIII d.C., exemplificado pelo conjunto monástico de Ellora, que possui grutas dedicadas ao Budismo, ao Jainismo e ao Hinduísmo. A partir dessa época, a construção desse tipo de monumento arquitetônico entrou em declínio na Índia. Nesse sentido, a área geográfica composta pelo planalto do Deccan e a faixa litorânea do Konkan foi a única a apresentar um desenvolvimento ininterrupto dessa tradição construtiva, perpetuada ao longo de aproximadamente um milênio. No restante do subcontinente indiano, por sua vez, esse desenvolvimento ocorreu em menor escala e de maneira esporádica.

A estrutura da formação geológica nessa região foi em muitos casos responsável pelas formas arquitetônicas dos monumentos. No Konkan, e nas demais áreas periféricas dessa formação rochosa, as montanhas possuem características específicas: são baixas e com as laterais pouco íngremes. A primeira necessidade construtiva era obter fachadas planas verticais, a fim de escavar as grutas. Os arquitetos conseguiam criar esses planos ao retirar a rocha da parte frontal da montanha, o que resultava na formação de um pátio aberto, com paredes laterais, diante da fachada do monumento. Esse elemento se tornou recorrente nesse primeiro tipo de gruta - como pode ser observado em Kanheri (Fig. 3), Kuda, e algumas das grutas de Ellora. Por outro lado, a cadeia central das montanhas Sahyadri e os montes adjacentes, na área do Mawal, apresen- 


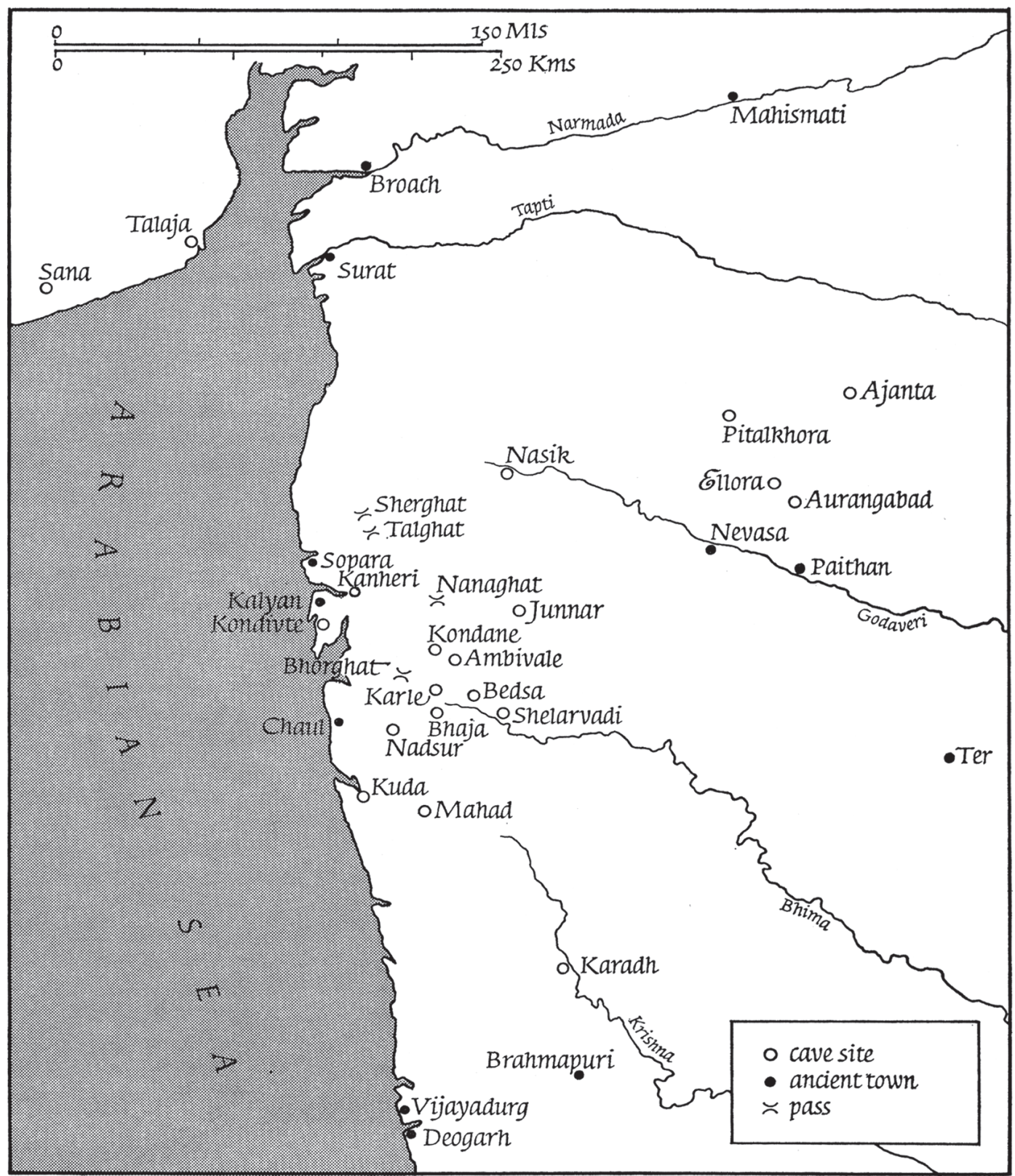

Fig. 2. Mapa das regiões do Konkan e Deccan na costa oeste de Maharashtra com os principais conjuntos de grutas budistas talhadas na rocha (em Dehejia 1972:12).

tam escarpas colossais. Nesses locais surgiu um segundo tipo de fachada, pois era possível talhar as grutas diretamente nas paredes escarpadas sem a necessidade de muito trabalho preliminar exemplos desse tipo ocorrem em Ajanta (Fig. 4), Bhaja e Karli. As grutas foram geralmente talhadas na área central, entre a base e o topo das montanhas, mas sua localização podia variar de acordo com as características específicas da área circunvizinha. Nos casos em que os vilarejos ficassem situados em vales, estuários ou à beira mar, as grutas foram construídas na parte mais alta da encosta dos morros; já no planalto, as cidades costumavam ficar acima das grutas que 
Rotas seculares e monastérios talhados na rocha: a retórica da paisagem sagrada budista na costa oeste da Índia Antiga. Revista do Museu de Arqueologia e Etnologia, São Paulo, 17: 39-67, 2007.

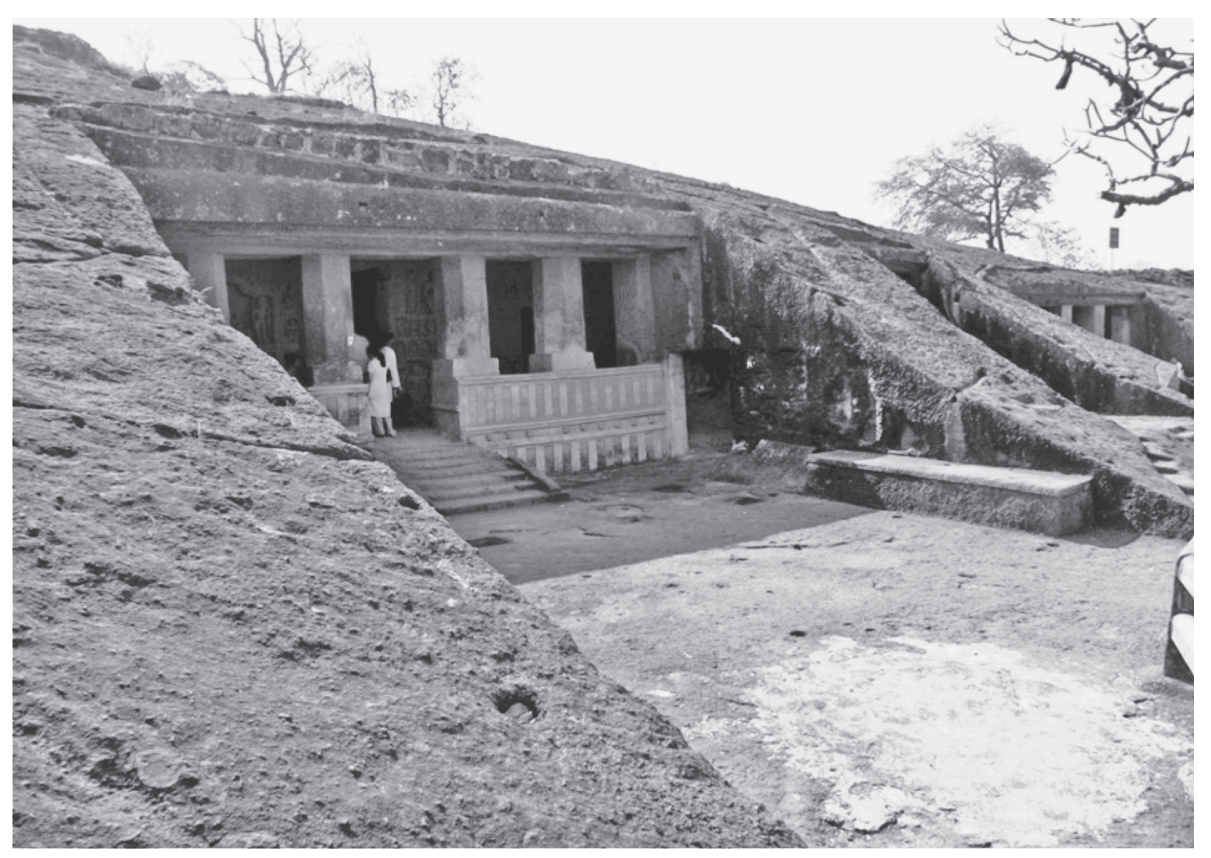

Fig. 3. Fachada das Grutas 67 a 69 do conjunto monástico de Kanheri (Aldrovandi 2004).

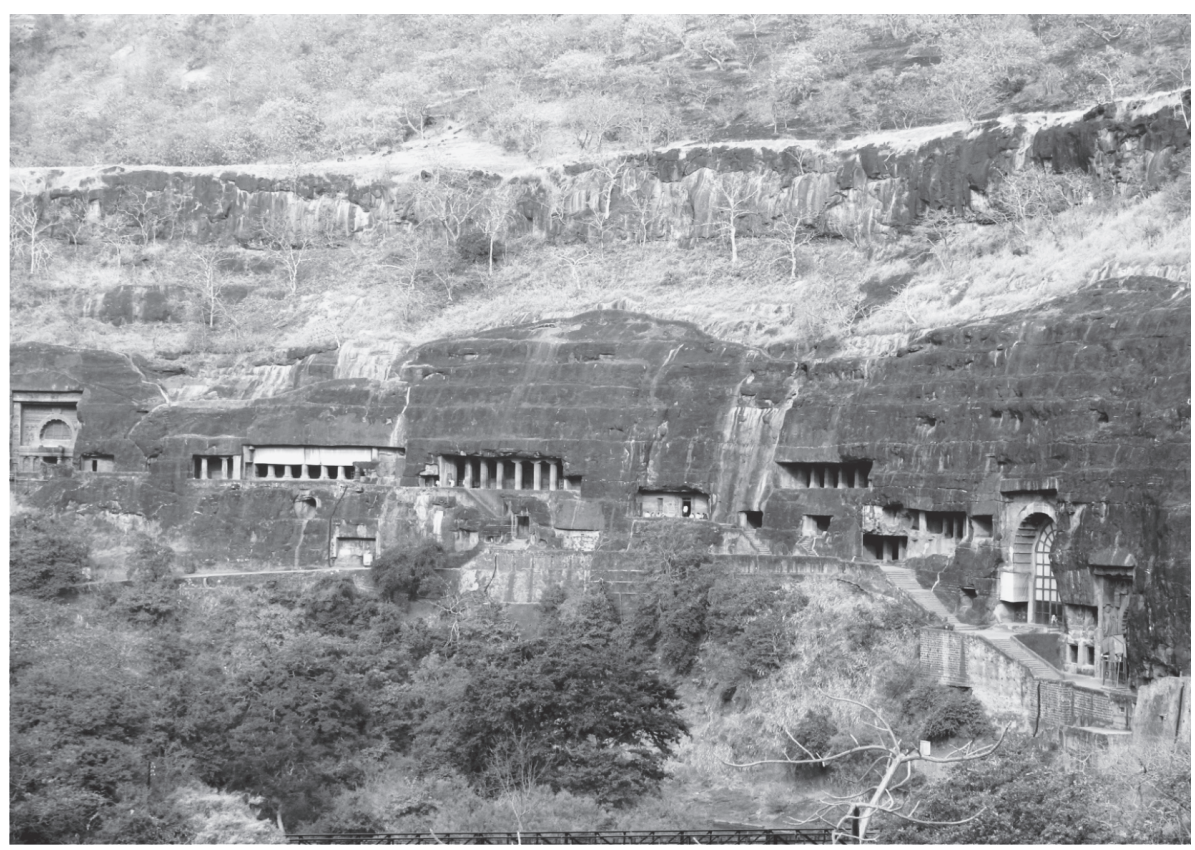

Fig. 4. Vista das grutas do conjunto monástico de Ajanta (Aldrovandi 2004). 


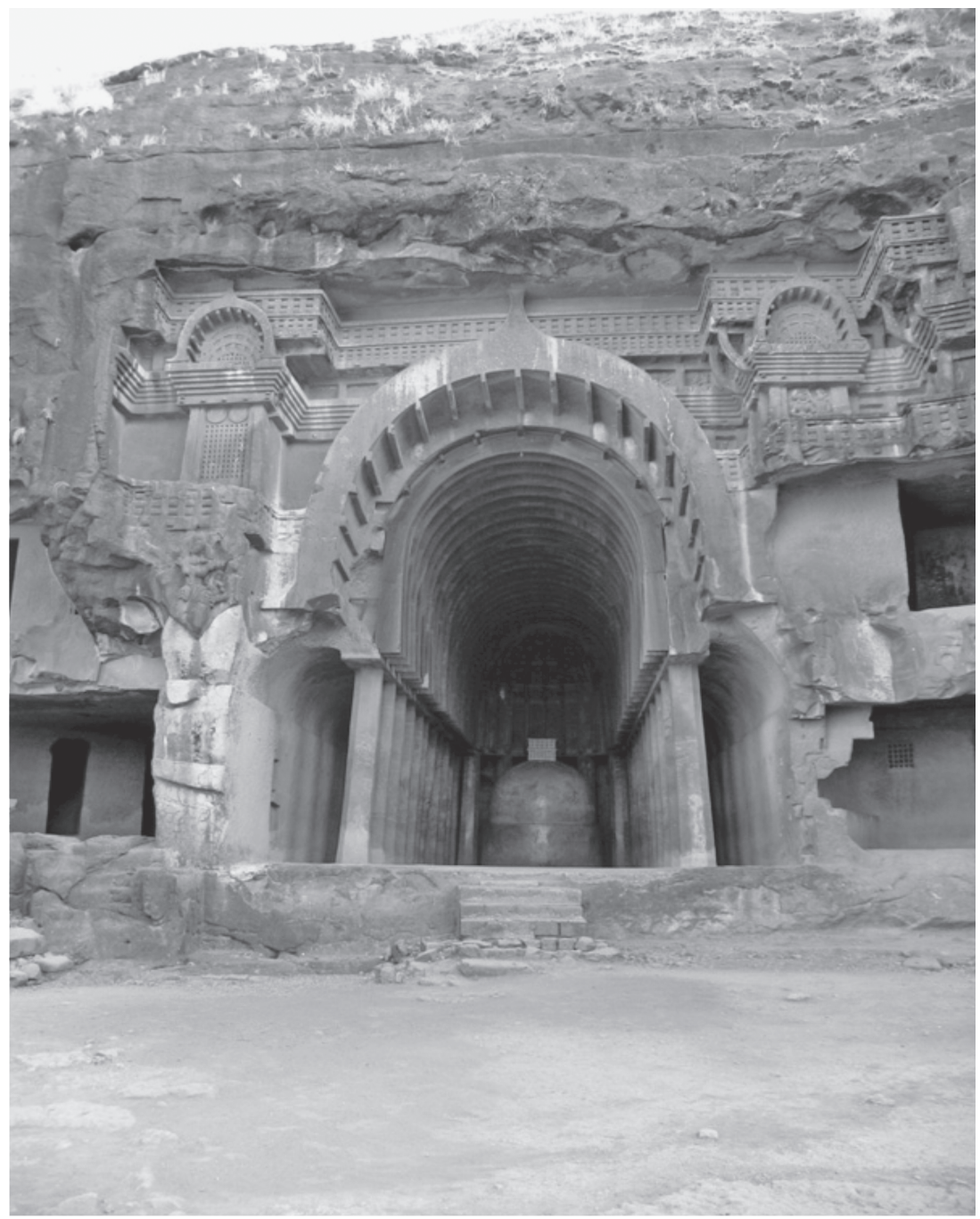

Fig. 5. Fachada do caityagRha do conjunto monástico de Bhaja, c. 100-70 a.C. (Aldrovandi 2004).

foram escavadas nos paredões escarpados das formações. A natureza da formação rochosa também determinou as dimensões das grutas. $\mathrm{Na}$ região do Sahyadri-Mawal os monumentos são geralmente maiores e mais altos que aqueles existentes no Konkan.

Outra variável importante dessa paisagem sagrada refere-se à quantidade de grutas existen-

(2) Os vocábulos em sânscrito, com exceção dos nomes próprios, localidades e obras literárias, foram grafados pelo sistema "Tokyo-Standard". tes em cada conjunto monástico. Enquanto alguns desses monastérios possuem apenas uma ou duas grutas - como Chaul II e III, ou Gomasi -, outros desses centros - como Kanheri -, têm mais de uma centena de monumentos num único sítio, o que fornece evidências importantes das mudanças na demografia budista durante o desenvolvimento dessa tradição arquitetônica. As grutas, por sua vez, apresentam as mais diversas plantas, bem como funções distintas que variam de salas ou salões amplos construídos para abrigar estupas e imagens - os caityagRha ${ }^{2}$ (Figs. 5 e 6) -, a 


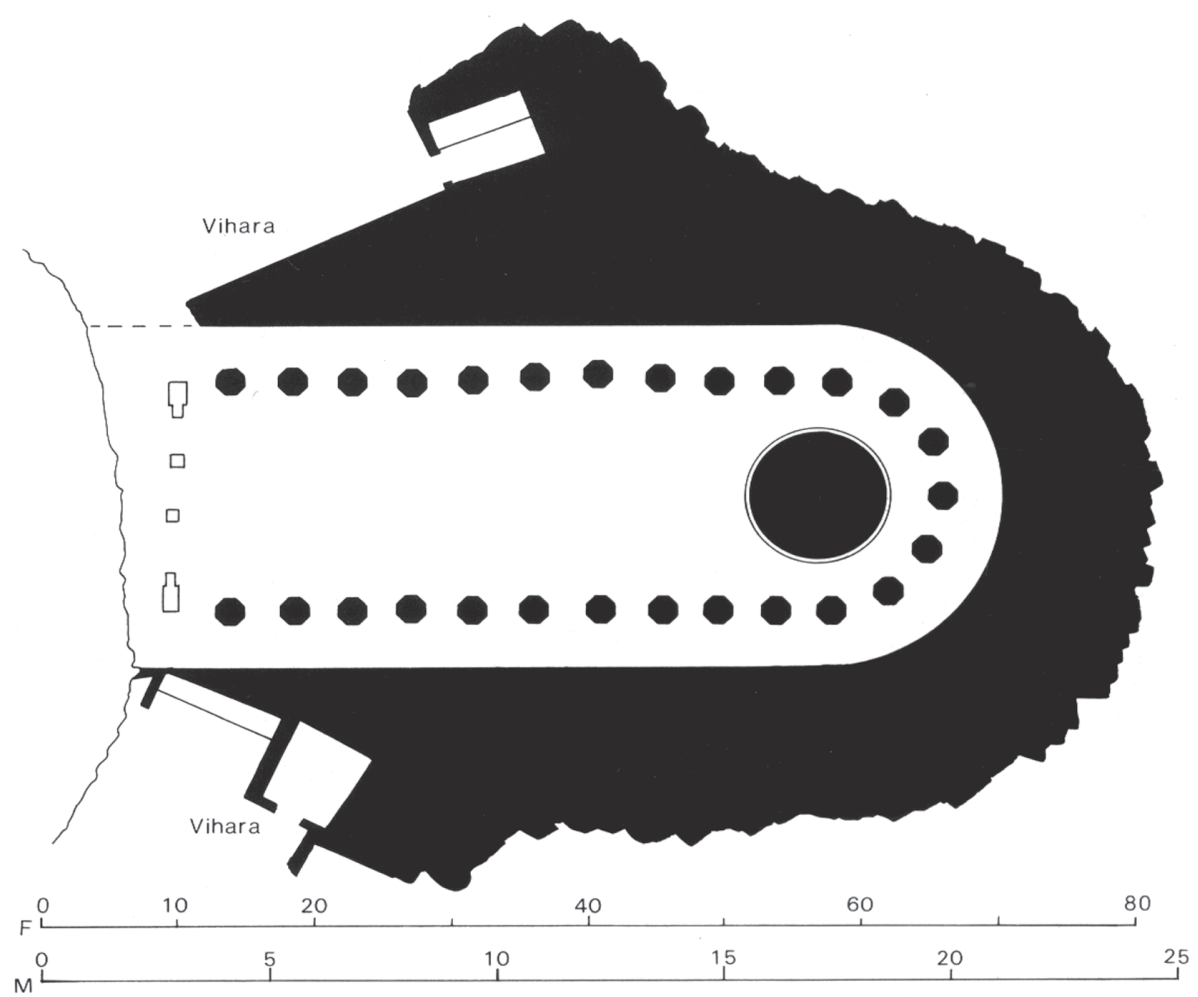

Fig. 6. Planta do caityagRha do conjunto monástico de Bhaja, c. 100-70 a.C. (em Huntington 1985:77).

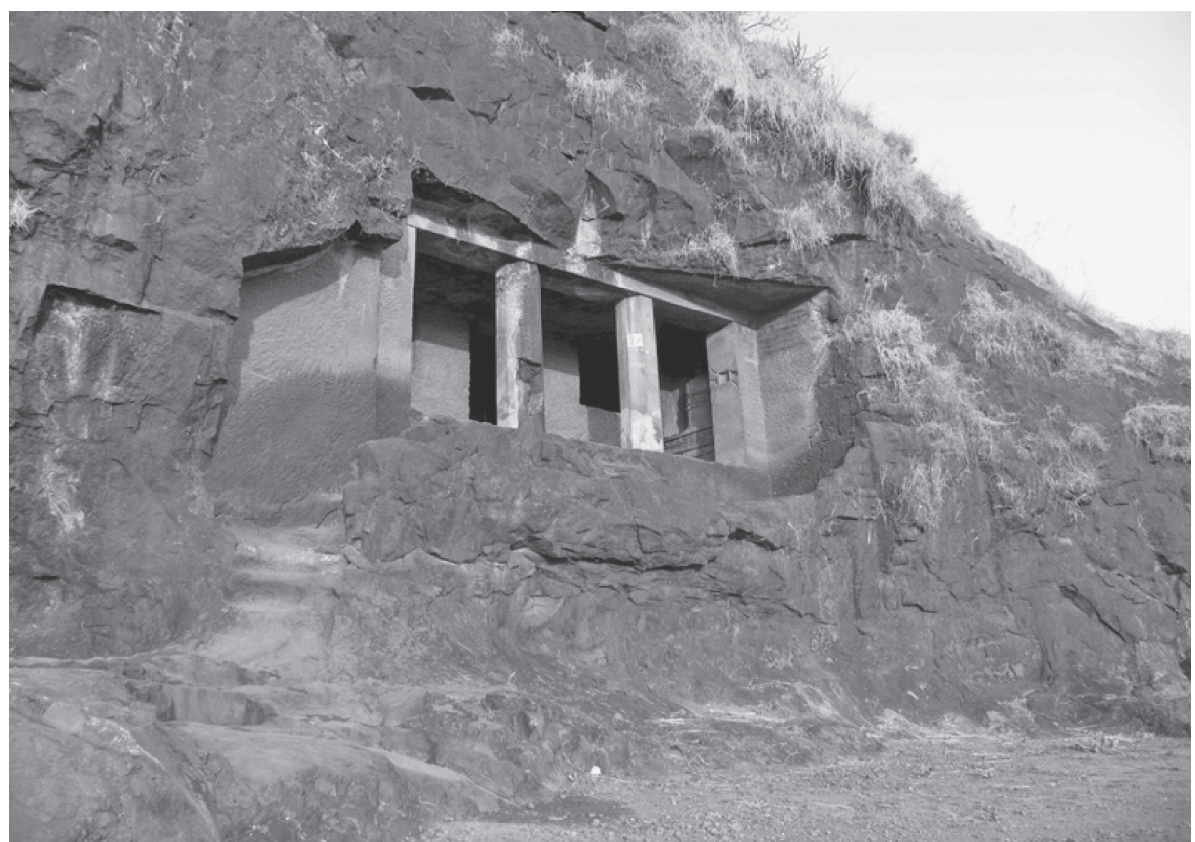

Fig. 7. Fachada externa do leNa 27 no conjunto monástico de Mahad (Aldrovandi 2004). 


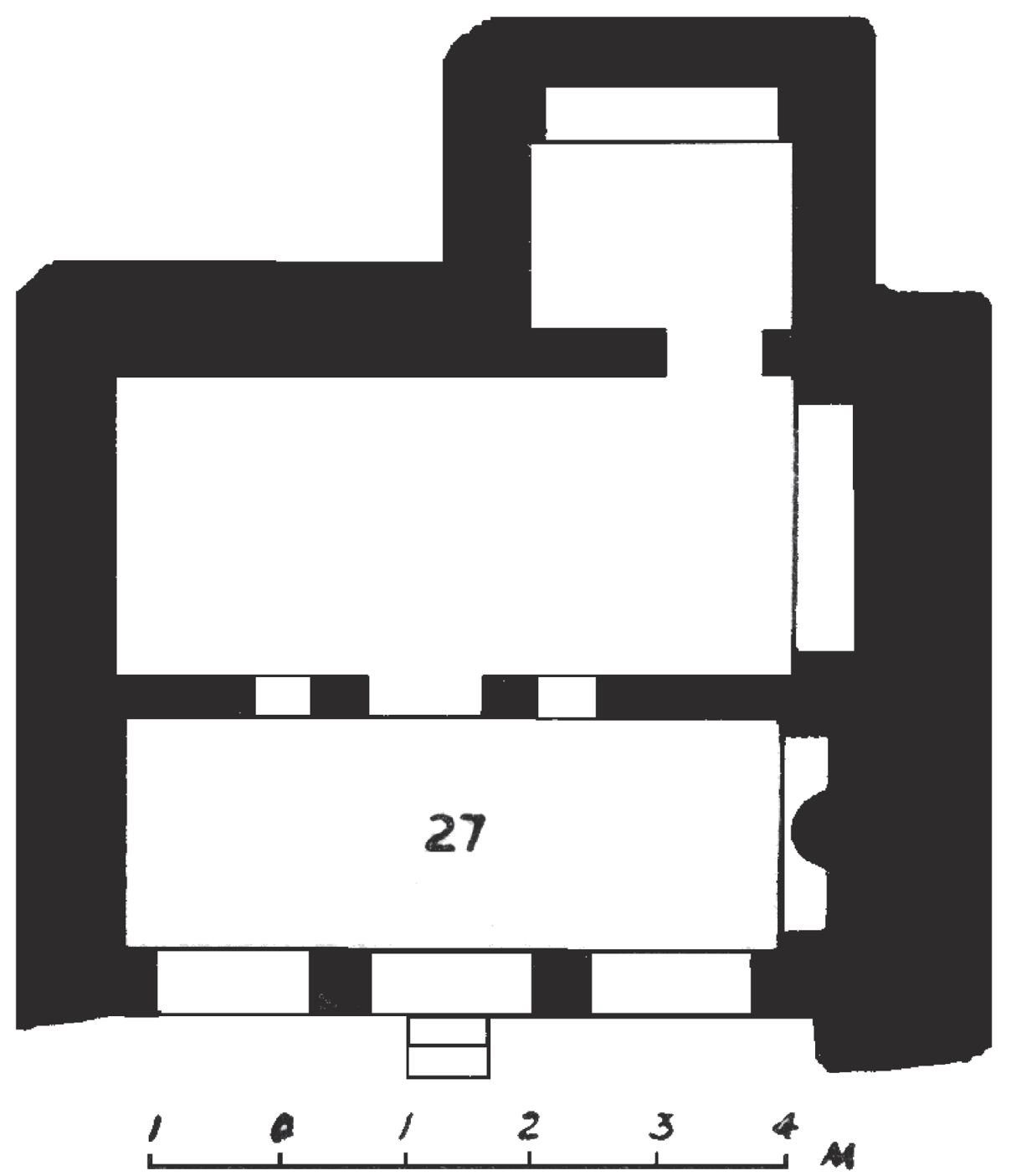

Fig. 8. Planta da Gruta 27 do conjunto monástico de Mahad (adaptada de Nagaraju 1981: fig.53).

pequenas celas e unidades de habitação monástica mais elaboradas - os leNa ou vihAra (Figs. 7 e 8). $\mathrm{O}$ estudo extensivo dos padrões arquitetônicos presentes nesses monumentos, realizado por Nagaraju (1981), menciona ainda os maTapa salas simples, com ou sem bancos e varanda, cuja função pode ter estado associada a refeições, estudo ou abrigo de viajantes; os poDhi cisternas para armazenamento de água potável e, em casos raros, para banho; os asanapeDhikA bancos e bancadas, geralmente nas áreas externas das grutas; e os koDhi - espécies de nichos abertos na rocha, cuja função permanece desconhecida.

A maior parte dos centros monásticos está situada em áreas de densidade pluviométrica maior. As chuvas sazonais, entre junho e setembro, permitiam o armazenamento de água para o restante do ano. $\mathrm{O}$ suprimento de água durante o verão e inverno era garantido pelas numerosas cisternas talhadas ao lado das grutas, que eram abastecidas durante as monções por meio de dutos escavados na rocha (Figs. 9 e 10). 
Rotas seculares e monastérios talhados na rocha: a retórica da paisagem sagrada budista na costa oeste da Índia Antiga. Revista do Museu de Arqueologia e Etnologia, São Paulo, 17: 39-67, 2007.
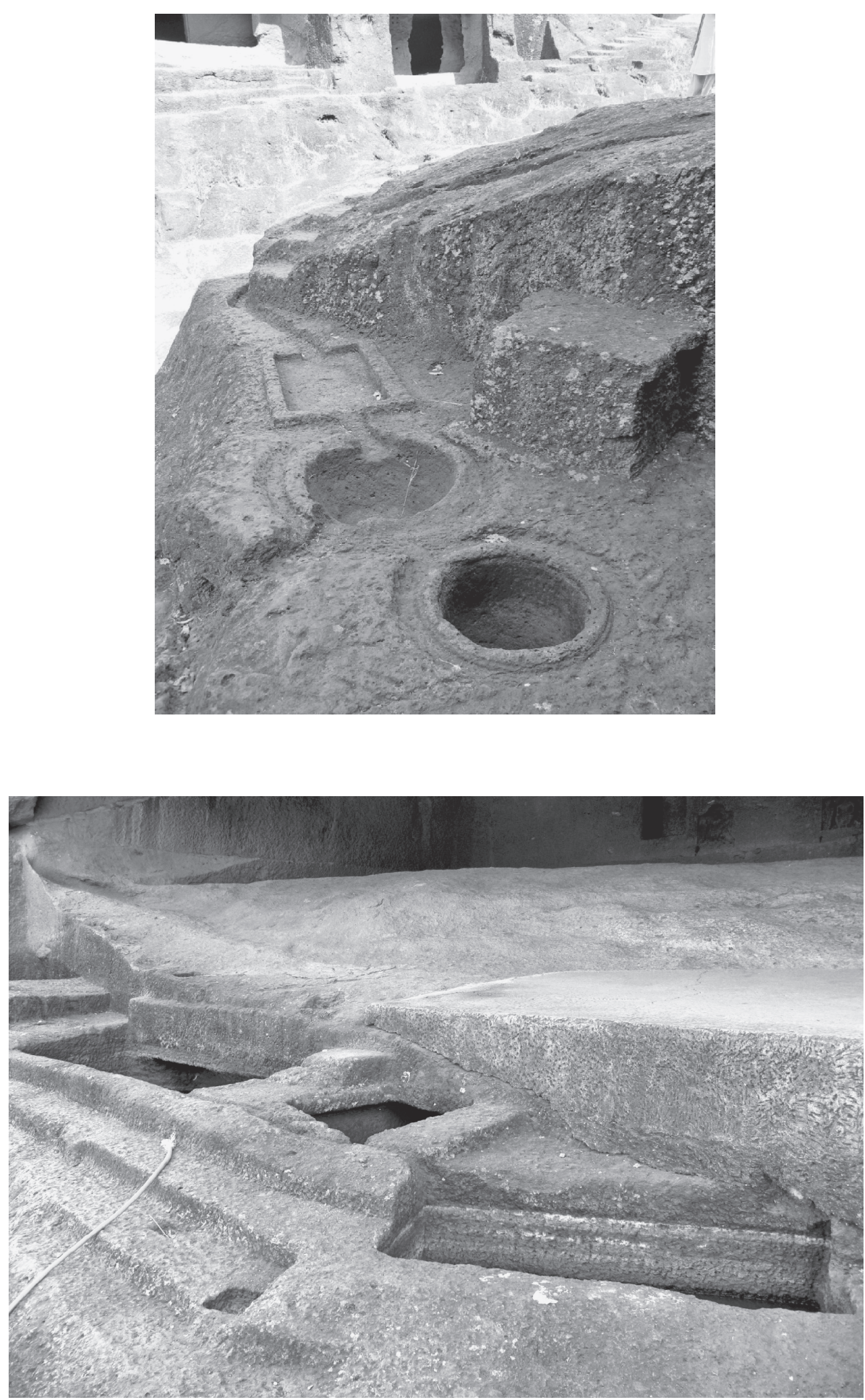

Figs. 9 e 10. Sistema de captação de água e cisternas no conjunto monástico de Kanheri (Aldrovandi 2004). 
Evidências da tecnologia construtiva empregada nesses conjuntos arquitetônicos podem ser obtidas, principalmente, por meio das escavações inacabadas. Os blocos eram retirados com o auxílio de ferramentas rudimentares e as paredes aplainadas com auxílio de cinzéis, cujas marcas ainda podem ser observadas em algumas grutas. As formas arquitetônicas encontradas nos conjuntos mais antigos revelam um desenvolvimento iniciado possivelmente a partir da imitação dos edifícios contemporâneos construídos em madeira. Nessa fase inicial, a arquitetura recebeu a complementação de elementos em madeira como nos casos de Karli e Bhaja. Numa fase subseqüente, esses elementos funcionais foram transpostos integralmente para as construções na rocha. Partes estruturais, antes confeccionadas em madeira, passaram a ser talhadas na própria rocha e são consideradas evidências da gradual familiaridade técnica dos artesãos diante desse novo suporte. Nagaraju (1981:67) observa que os primeiros artesãos mencionados em inscrições eram carpinteiros - vaDhaki -, termo que aparece em Karli e Kanheri. Mas para Dehejia (1972:77), essa mudança construtiva não pode ser considerada uma evidência confiável para estabelecer o desenvolvimento e a cronologia relativa das grutas, como muitos pesquisadores acreditam.

As características específicas dessa arquitetura talhada na rocha permitiram que esses conjuntos monásticos fossem preservados no registro arqueológico ao longo dos séculos. A profusão e continuidade dos conjuntos de grutas aqui tratados possibilitam compreender o desenvolvimento da tradição arquitetônica budista nessa área geográfica. Essas peculiaridades permitem, por sua vez, observar que esta foi uma arquitetura totalmente adaptada às condições geográficas naturais da região e, como veremos, às mudanças políticas, econômicas e religiosas a que esteve sucessivamente exposta.

\subsection{Contextualização histórica}

O propósito de traçar um breve histórico da fase inicial de desenvolvimento do período abordado nesta pesquisa - entre o século III a.C. e III d.C. - é delinear um panorama da região analisada que, embora sucinto, seja capaz de fornecer elementos fundamentais à compreensão contextual da área em questão. O Período Histórico Inicial do Sul da Ásia abrange o intervalo aproximado entre 600 a.C. e 400 d.C. (ver Ray 2006:71), e esteve diretamente associado ao reaparecimento das cidades e unidades sociopolíticas complexas, especialmente na região de Magadha, mas também em outras áreas geográficas do subcontinente.

Assim como nas demais regiões, as fontes históricas existentes sobre o início do período histórico no Deccan e Konkan são relativamente escassas, mas as evidências arqueológicas sistematicamente pesquisadas em Maharashtra pelo Deccan College forneceram dados importantes para compreensão do processo de surgimento das cidades do período Histórico Inicial. Apesar de essa região ter freqüentemente sido considerada uma área secundária de formação estatal em relação à planície gangética (cf. Parasher-Sen 1993:66), os estudos comprovaram a existência de assentamentos desde o Neolítico superior (Sankalia 1974:471-512). Esses sítios apresentaram continuidade no Calcolítico, especialmente representado pelo chamado período Malwa (1800 a 1500 a.C.). Em seguida, observou-se uma grande expansão dos assentamentos agrícolas no período Jorwe (1500 a 1100 a.C.) e Jorwe tardio (1100 a 800 a.C.), que marca o início da Idade do Ferro na região (Allchin 1982:271-77, 327).

A razão da proposição de uma urbanização abrupta ou artificial na região do Deccan é, segundo Morrison (1995:204-207), conseqüência do conhecimento parcial da arqueologia dos períodos anteriores, particularmente a Idade do Ferro e o período Megalítico. A região, antes da época em questão, já possuía uma população de agricultores sedentários, com uma estrutura econômica especializada bem desenvolvida e padrões de diferenciação social em unidades sociopolíticas pré-Maurya baseadas em chefias, como por exemplo, nos sítios Calcolíticos em Prakash, Nevasa e Nasik que, apesar de apresentarem em certos casos indícios de abandono, mais tarde foram importantes cidades Satavahana. 
Nos séculos anteriores ao surgimento dos Satavahana, a História política da área geográfica em questão esteve relacionada à hegemonia de Magadha e do Império Maurya. O imperador Chandragupta Maurya é considerado o responsável pela anexação desses territórios durante seu governo, mas a data exata da expansão do império de Magadha, ao sul dos Vindhya, é incerta. As inscrições de Ashoka, em Sopara, na costa de Mumbai, Sanci, na Índia central, Erragudi, Maski, Brahmagiri e Kopbal, no sul do Deccan, atestam que essa área esteve sob o domínio dos Maurya. As evidências arqueológicas fornecidas, por exemplo, pelos sítios de Nasik, Nevasa e Chaul confirmam os contatos existentes entre a região do Deccan e o norte da Índia - região de Magadha, desde o período Maurya. As razões para a conquista Maurya do Konkan são atribuídas ao domínio dos recursos e do comércio da região (Thapar 2000:112-113).

Durante a segunda metade do século III a.C. até III d.C., essas áreas fizeram parte de uma unidade sociopolítica que esteve, na maior parte do tempo, sob o domínio do império Satavahana. O período de surgimento e desenvolvimento dos conjuntos da arquitetura monástica budista esteve, portanto, diretamente associado às dinastias Satavahana, que reinaram nas regiões do Deccan, Andhra Pradesh e nos vales dos rios Krsna e Godavari. Nos Purana, os Satavahana são chamados Andhra e esse período é, por isso, algumas vezes chamado Andhra ou Andhra-Satavahana (Huntington 1985:90-91).

A cronologia do período ainda apresenta problemas e, por essa razão, não está ainda esclarecido se o início do poderio dos Satavahana teria se dado durante, imediatamente após, ou somente depois da desintegração do império Maurya. Algumas teorias optaram pela sucessão direta dos Maurya e, nesse caso, os Satavahana são retratados como um poder imperial centralizador e expansionista, nos mesmos moldes que seus antecessores (ver Sastri 1966; Mirashi 1955). Outras propostas favorecem uma origem mais tardia e organização descentralizada (ver Ray 1986, 2003; Parasher-Sen 1993; Shastri 1987; Morrison
1995; Sinopoli 2001). No entanto, as datas permanecem controversas.

As principais evidências utilizadas para o estabelecimento de uma cronologia são as fontes textuais. Os Purana fornecem duas cronologias dinásticas: uma mais longa, de 460 anos, utilizada por aqueles que defendem uma influência Maurya mais direta; e outra mais curta, na qual os Satavahana teriam surgido durante o século I a.C. No entanto, as listas dos reis e dinastias fornecidas pertencem a eras desconhecidas. Da mesma maneira, existem estudiosos que postularam a origem geográfica dos Satavahana no oeste do planalto do Deccan (Dehejia 1972; Sinopoli 2001; Thapar 1966:65-66; Morrison 1995:208-210), enquanto outros propuseram o leste da Índia, junto ao vale do rio Krsna e Godavari (Shastri 1987; Ray 1986).

Apesar das discrepâncias cronológicas e geográficas, o início dessa dinastia e sua expansão territorial estão atestados no registro arqueológico por meio das inscrições e da numismática. Alguns reis, mencionados nos Purana, aparecem nas moedas e inscrições do Deccan e do vale do rio Krsna. Por outro lado, há também indícios de que os Satavahana não possuíam um controle territorial centralizado, pois muitos nomes de reis que aparecem nas moedas não são mencionados nos Purana, isso pode indicar que eles eram apenas governantes locais. A distribuição dessas moedas apresenta um padrão geográfico circunscrito, o que corrobora essa idéia (ver Sarma 1980; e Dutta 1990).

Um outro indício da descentralização durante o império dos Satavahana foi a existência de diferentes capitais, embora ainda não haja certeza sobre seu sincronismo ou diacronismo. Essa descentralização não estaria associada à formação de uma única unidade sociopolítica, mas a grupos competitivos ou cooperativos de elites políticas (Morisson 1995:213). Linhagens dinásticas contemporâneas parecem ter estado dispersas pela região, como os Mahabhoja, que aparecem nas inscrições de Kuda (ver Nagaraju 1981:340341), os Maharathi (Ray 2003:145-146), e os Kura, na região de Kolhapur (ver Nilakanta 
Sastri 1957:338). Por outro lado, algumas inscrições registram a existência de um sistema de taxação e de oficiais territoriais, o que indica a presença de uma autoridade imperial. Essas evidências apontam para a supremacia dos Satavahana como governantes regionais em períodos dinásticos específicos, nos quais teria havido uma centralização política e administração mais efetiva na região do Deccan, intercalados por épocas de fragmentação decorrente da invasão do Ksaharata Nahapana (Dehejia 1972:29-30; Sinopoli 2001:177).

Assim, durante a época mais tardia do domínio Satavahana, é possível que tenha existido um controle territorial mais amplo. Existem, por exemplo, inscrições que mencionam o reinado de Shri Satakarni em Sanci (Luders 1912: n. ${ }^{\circ}$ 346) e nas grutas de Nanaghat (ver Fergusson e Burgess 1880:264; Nagaraju 1981:24). Uma inscrição em Nasik, datada do século I d.C., menciona que um rei Satavahana plantou milhares de coqueiros na costa oeste (Kosambi 1976:185-189; Gokhale 1999:282). Algumas inscrições indicam que essa dinastia era poderosa o bastante para realizar alguns dos mais elaborados sacrifícios védicos, como o rAjasUya e o aCvamedha. Os reis Satavahana apoiavam diferentes religiões e parecem ter sido flexíveis em suas tradições culturais (Thapar 2000:119), o que reflete uma combinação de aspectos políticos e religiosos capazes de favorecer sua inserção num meio social heterogêneo.

Embora na maior parte desse período as regiões do Deccan e Konkan estivessem sob domínio dos Satavahana, até mesmo essa supremacia esteve sujeita a épocas de declínio, como durante a ocupação dos territórios pelos reis Ksaharata ou Ksatrapa, dos Abhira. Esta foi uma linhagem dos Shaka que reinou entre os séculos II e III d.C. e teria sobrepujado os Satavahana em Maharashtra, depois no Konkan e Gujarat (Nagaraju 1981:22-23). Baseado nos relatos de Ptolomeu, Warmington (1928:112) menciona nove cidades regidas pelo rei Tiastanes, um Ksatrapa-Shaka da linhagem de Chastana, que governava em Ozene (Ujjain) e foi visitado por mercadores gregos, e outras sete cidades, dentre elas Ter e
Paithan (Tagara e Paethana, no Périplo; Baethana, em Ptolomeu), esta última, a capital do rei [Siri]ptolomaeos, isto é, o rei Andhra, Sri Pulomavit ou Pulumayi II (138-170 d.C.). Em Nasik encontra-se uma inscrição mais tardia em que Gautamiputra Satakarni, um célebre rei Satavahana, destitui a família dos Ksatrapa Ksaharata, por volta de 124 d.C. Durante seu reinado o controle dos Shaka sobre passagens estratégicas foi extinto - como as vias de acesso a Nasik e Karli - e o poder Satavahana recuperado (Huntington 1985:166-167). No entanto, as fontes mencionam que em 130 d.C., os Ksatrapa que dominavam a região norte do império Satavahana anexaram grandes áreas junto ao rio Narmada (Mirashi 1955; Yazdani 1960:97-108).

Historicamente, o período foi caracterizado pelas rivalidades entre os Satavahana e Ksaharata, mas apesar dos conflitos políticos, as regiões dominadas por essas dinastias presenciaram, como veremos a seguir, um crescimento econômico surpreendente. Nessa mesma época, o norte da Índia estava envolto pela instabilidade política decorrente do declínio e fragmentação do império Maurya.

O declínio do império Satavahana ocorreu, provavelmente, após a morte de Sri Yajña Satakarni, no ano 201 d.C., e sua extinção deuse por volta do ano 224 d.C. O território foi, então, dividido em pequenos principados. Algumas das grutas de Kanheri, escavadas nesse período, apresentam qualidade inferior especialmente as esculturas presentes nos capitéis -, o que pode ser um indício das pressões políticas existentes e um prenúncio da desintegração do império Satavahana (cf. Huntington 1985:174). Por volta do ano 248 ou 249 d.C., os Abhira restabeleceram sua supremacia no Deccan, no entanto, as evidências existentes sobre essa dinastia são mínimas, como nos Purana, em que há registros de uma dinastia de dez Abhira (Mirashi 1955).

\subsection{As trocas comerciais}

O desenvolvimento socioeconômico observado nas regiões do Konkan e do Deccan durante os primeiros séculos a.C. e d.C. foi 
decorrente da fase de urbanização iniciada durante o período Maurya. A unificação alcançada pelo império de Magadha, no norte da Índia, havia tornado essas regiões parte de uma unidade sociopolítica organizada, o que favoreceu o crescimento das trocas comerciais. Durante essa época, parte dos oficiais e soldados do império tinham passado a residir nessas áreas e os contatos comerciais podem ter crescido devido às condições políticas mais estáveis estabelecidas na região.

Assim como na esfera política, houve uma tendência a considerar a organização econômica dessas regiões como um mero produto importado da região gangética (Morrison 1995: 203). No entanto, como vimos, as pesquisas arqueológicas confirmaram a existência de cidades Satavahana cuja ocupação remonta ao período Calcolítico.

Evidências do aumento dos contatos entre essas regiões estão registradas nas fontes literárias da época, assim como nos registros arqueológicos. Existem referências específicas à região no Ramayana, que mencionam lugares e rios do Deccan, como Chitrakuta, Nasika, Godavari e Narmada. No Mahabharata (Sabhaparva) estão descritos eventos que teriam ocorrido em Nasika, Sanjayanti (Sanjan) e Karahata (Karhad); o épico também cita Shurparaka (Sopara) como uma cidade sagrada em Aparanta, esse porto também é mencionado no Ramayana e na literatura budista primitiva. O Mahaniddesa refere-se à Surata (Surat) e Shurparaka como entrepostos comerciais (Yazdani 1960:16-27; Charpentier 1927:111).

O processo de formação e estruturação de uma nova sociedade e o desenvolvimento econômico que teve início durante o império Maurya apresentou continuidade durante o período Satavahana. Esse crescimento ininterrupto da economia foi evidenciado nos níveis estratigráficos de sítios arqueológicos da região que apresentaram níveis habitacionais mais complexos - com material arqueológico mais abundante -, e indícios de prosperidade econômica (Chandra 1977:100).

Sítios arqueológicos de cidades como Nevasa, Brahmapuri (Kolhapur), Nasik,
Prakasa, Kaundapur, Dhatva (no Surat), Bahal, Ter e Chaul forneceram fragmentos da Cerâmica Preta Polida (BPW - Black Polished Ware) que é originária da região gangética; além dela, foram encontradas moedas e objetos de mesma procedência (ver Sankalia e Dikshit 1952; Sankalia e Deo 1955; Sankalia et al. 1960; Thapar 1966; Gogte e Aldrovandi 2005. 2006).

Nessa época, as atividades comerciais crescentes entre as regiões do Konkan e do Deccan foram impulsionadas pela reorganização política e pela criação de uma rede de rotas comerciais para o escoamento das mercadorias. A mobilidade e o dinamismo econômico observados a partir desse período foram fatores viabilizados pela existência de um amplo sistema de comunicação que interligava várias partes do subcontinente indiano. Essas vias ligavam o extremo sul como Madurai e Arikamedu ao estado de Karnataka e, no Deccan, chegavam a cidades como Kolhapur, Karad, Sirval e Ter. Cidades do período Satavahana foram encontradas ao longo dessa rota. A partir de Ter a rota seguia até Nasik, via Junnar. Paithan, capital do império, era ligada por estradas a Ter, Nasik, Bahal e Junnar, via Nevasa (ver Deshpande 1959:58-59). As cidades do norte da Índia possuíam rotas até Paithan e Nasik (Nilakanta Sastri 1957:437; Nagaraju 1981:30). O Périplo do Mar Eritreo informava que as rotas de Paithan até Barygaza eram feitas em caravanas em grandes trilhas (Yazdani 1960:138).

$\mathrm{Na}$ era Satavahana e Ksaharata, a economia organizou-se em vários setores. As evidências arqueológicas e em especial a epigrafia apontam duas camadas sociais, nobres e comerciantes, como grupos econômicos poderosos (Figs. 11 e 12). Na esfera social, esses grupos pertenciam às varNa dos kSatriya e vaiCya e ocupavam posições de elite na sociedade local.

Os comerciantes possuíam funções específicas que incluíam, como confirmam as inscrições, o comércio de perfumes, metais e ouro. Naquela época, havia mercadores para o comércio de longa distância - os sathavAha -, mencionados em três inscrições em Kuda 


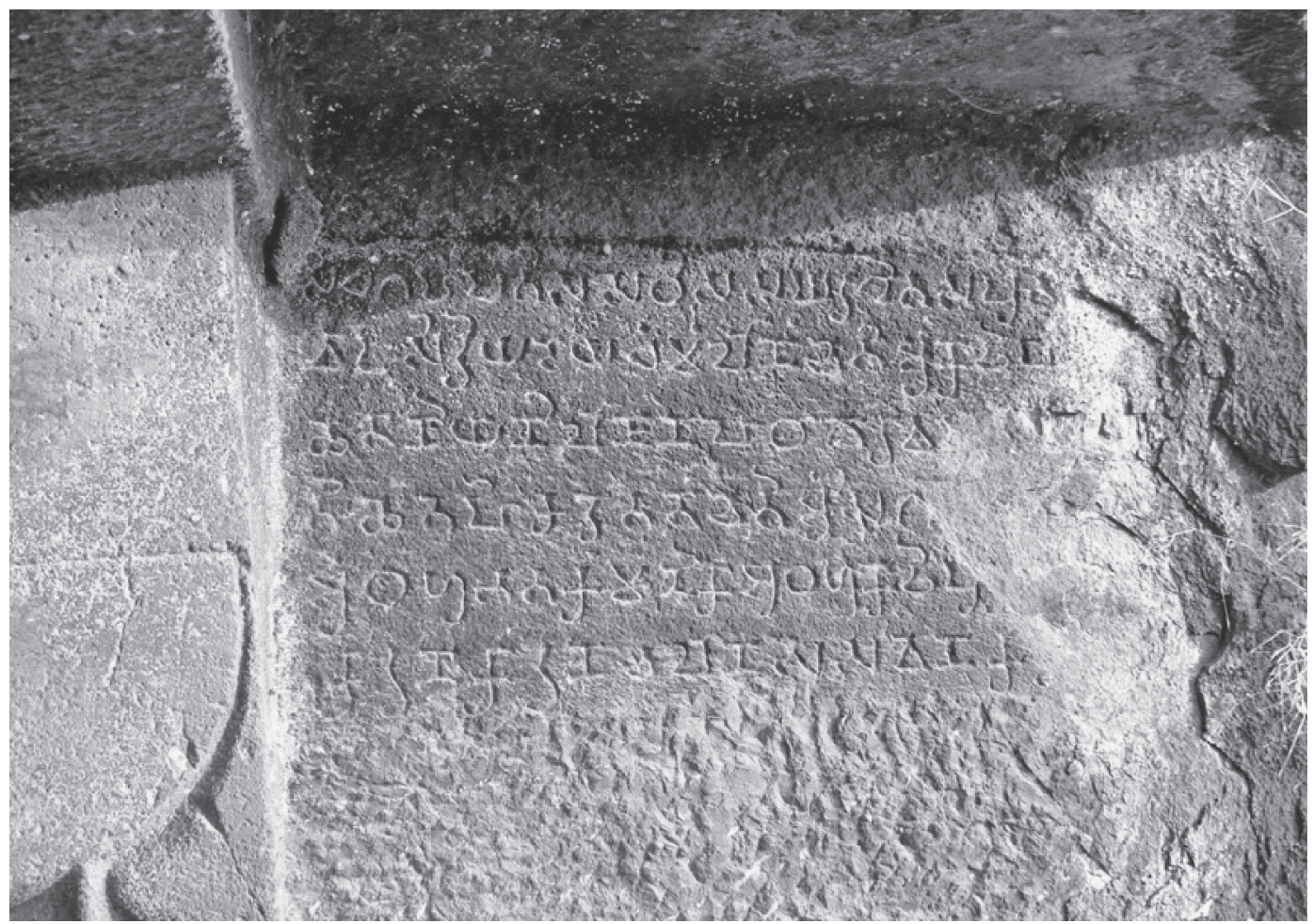

(Nagaraju 1981:40). Segundo Cimino (1994:175-176), eles eram chefes das caravanas, mas o transporte das mercadorias era feito por homens de tribos nômades chamados Lamani ou Vanjara que possuíam centenas de touros à disposição. ${ }^{3}$

As inscrições presentes nos conjuntos monásticos budistas fornecem informações relevantes sobre o movimento comercial na

(3) Até os dias atuais existem assentamentos - chamados tanda - desses tribais que podem ser observados junto às grutas budistas ao longo das antigas rotas comerciais. Curiosamente, as mulheres tribais vestem roupas coloridas e ornamentos de prata, entre eles o mais apreciado é um colar de moedas, chamado dinaramala, pois era feito com imitações (bullae) dos denarii romanos. Perto de Ter (Pune) há um bairro chamado Hinglajvali, no qual há um templo em que a deusa Hinglajmata é adorada. Essa deusa é a principal divindade dos tribais Vanjara e Lamana que, vindos de locais distantes em Maharashtra visitam o templo. A comunidade dos Vanjara é conhecida em toda a Índia e a terra natal da deidade Hinglajmata parece ter sido o Paquistão (ou Baluchistão), às margens do rio Hinglaj. Cabe, ainda, atentar ao fato de que a montanha que abriga o conjunto budista Chaul I possui um templo hindu posterior, dedicado à mesma divindade Hinglaj (ver Gogte e Aldrovandi 2005-2006:263-264).

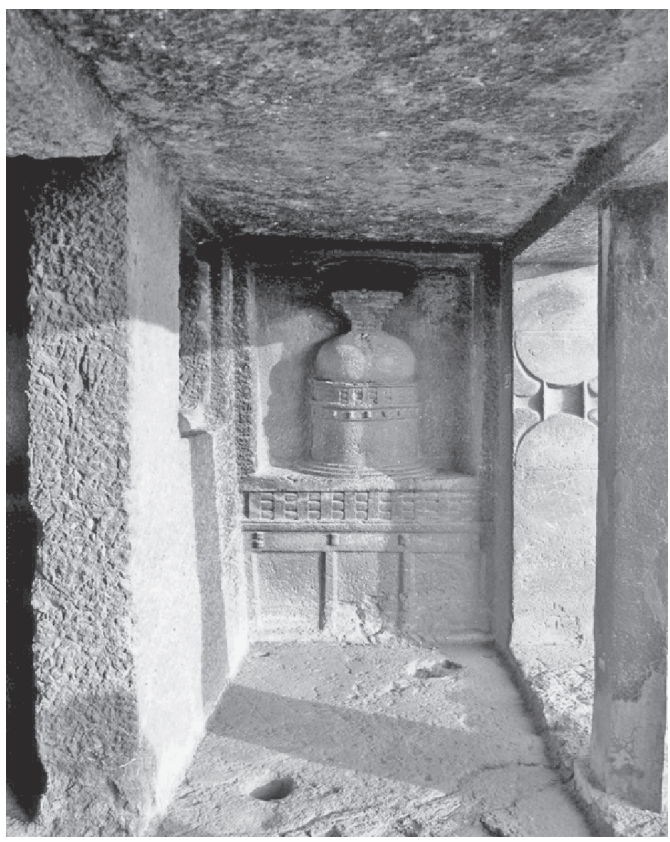

Figs. 11 e 12. Inscrição parcialmente danificada na parede esquerda do pátio da Gruta 27 do conjunto monástico de Mahad que registra a doação feita por um mercador chamado Vadisiri da gruta e do nicho com estupa em relevo na varanda (Aldrovandi 2004). 
região. Por meio dessas fontes, sabe-se que os mercadores comercializavam tanto em regiões próximas quanto nas distantes. As associações de mercadores - negama ou señhi (seNi ou CreNi) - existiram em cidades importantes como Dhenukàkata e Junnar. As inscrições de Kanheri mencionam Soparaganegama; e Kaliyanakasanegama (Nagaraju 1981:40).

Essas associações ou guildas parecem ter recebido doações e depósitos permanentes que respondiam por um excedente anual à base de rendimentos decorrentes do capital depositado. Uma inscrição no conjunto de Nasik menciona, por exemplo, que Usavadata, genro de Nahapana (dos Ksaharata) depositou 3000 $k A r C A p a N a$ (valor monetário) em duas guildas de tecelões de Nasik, com a garantia de que os lucros obtidos a partir dessa soma, a juros de $1 \%$ e $0,75 \%$, fossem utilizados na distribuição de mantos para os monges que habitavam aquela gruta; além disso, uma plantação com 8000 coqueiros foi incluída na doação dessa gruta (ver Thapar 1966, 1984, 2000; Ray 1986; 2003; 2006:77). Comerciantes de Dhenukakata aparecem, por exemplo, em inscrições em Pitalkhora, Kanheri e Karli. A localização da cidade de Dhenukakata é controversa (ver Burgess 1883:24; Senart 1903:47; Johnston 1941:208; Kosambi 1955:51; Nagaraju 1981:40; Thosar 1991; Cimino 1994:161), mas essa cidade aparece associada aos nomes de muitos yavana estrangeiros - , como veremos a seguir.

\subsubsection{O comércio ultramar e os estrangeiros}

Outro fator importante que envolve a atividade comercial da época é o aumento considerável do comércio marítimo. As trocas comerciais com mercados estrangeiros estão atestadas desde a proto-história, além de haver fontes textuais que confirmam a existência de contatos comerciais entre a Índia, Ceilão (Sri Lanka), Arábia e Egito, antes do império romano (ver Filliozat 1949).

O domínio parta e a crescente rivalidade com os romanos na disputa pelas rotas terrestres no oeste da Ásia, por volta do ano 175 a.C., pode também ter impulsionado o crescimento das trocas marítimas. No início do período Satavahana, os mercadores árabes e egípcios eram responsáveis por grande parte das atividades comerciais entre o oeste da Índia e o Mediterrâneo que, no final do século I a.C., passaram a ser administradas pelos romanos. Um pequeno tratado escrito por Agartharchides de Alexandria, em 110 a.C., fornece um panorama do comércio da época (Dehejia 1972:18). Durante o reinado de Ptolomeu (século II d.C.) foram criadas facilidades para os navegadores egípcios e Alexandria havia se tornado um enorme empório. Anteriormente, o comércio entre o mundo mediterrâneo e a Índia tinha sido facilitado pela abertura do canal que ligava o Nilo ao Mar Vermelho em 190 a.C. ${ }^{4}$

A fundação do Império Romano, por sua vez, trouxe paz, facilitou a comunicação, ampliou a segurança das rotas comerciais e criou um aumento considerável no volume de mercadorias importadas. Nessa época, os romanos já conheciam as monções que facilitavam o acesso dos navios à costa indiana e que são mencionadas por Hippalus em c. 45 a.C. A ocupação do Egito por Augusto, por volta do ano 30 a.C., ampliou o domínio romano sobre o Mar Vermelho e Arábico. Há registros de uma expedição enviada pelo imperador para assegurar o monopólio da rota marítima até a Índia. Enquanto na época de Hippalus apenas 20 navios por ano eram enviados ao subcontinente, nos registros de Estrabão (67 a.C. a 20 d.C.) esse número subiu para 120 navios por ano, e durante o início do império romano passou a um navio por dia [Geografia, XV]. A perplexidade do mundo político romano frente à evasão de dinheiro para os mercados estrangeiros (Índia, China e a península Arábica) foi registrada por Plínio, o velho [História Natural VIXXVI.101; XII-XLI-84], que menciona uma quantia de 100 milhões de sestércios ao ano, metade da qual cabia à Índia.

(4) Esses contatos foram descritos por Majumdar e Pusalkar (1953:619-621), ver também Nilakanta Sastri (1957:307); Yazdani (1960:130) e Casson (1986). O comércio de longa distância foi objeto de estudo de muitos pesquisadores como Wheller (1954), Huntingford (1980), Begley e De Puma (1992) e Ray (1986; 1988; 2003; 2006). 
O crescimento do comércio marítimo foi, em grande parte, responsável pela ampliação dos portos no oeste da Índia. Os documentos mais antigos a mencioná-los são o Périplo do Mar Eritreu e a Geografia de Ptolomeu. Dentre eles estão o de Barygaza (Bharuch, no Gujarate), Soupara (Sopara, no distrito de Thana), Calliena (Kalyan, também em Thana) e Symilla (Chaul, no distrito de Kolaba).

As trocas comerciais entre Roma e Índia puderam ser comprovadas por meio dos vestígios arqueológicos de origem mediterrânea encontrados em diferentes regiões do subcontinente. Os produtos romanos foram encontrados, por exemplo, em escavações nos sítios de Arikamedu, Ter, Nasik, Nevasa, Brahmapuri, Junnar, Kalyan, Chaul, Paithan, Amreli, e Devnimori (no Gujarate).

Uma grande quantidade de moedas romanas foi recuperada, principalmente, no sul da Índia. As moedas mais antigas pertenceram à República romana, séculos I e II a.C. e as mais numerosas são as dos imperadores Augusto e Tibério. Coimbatore, no sul da Índia forneceu um conjunto numeroso de moedas da dinastia Julio-Claudiana. Durante o século I d.C., Nero diminuiu a exportação de moedas; na época de Vespasiano e Adriano houve uma redução das importações, decorrente da situação econômica desfavorável, assim os romanos passaram a utilizar moedas antigas nas trocas comerciais. Os imperadores seguintes diminuíram gradativamente a percentagem de metal precioso na cunhagem e, após a divisão, o Império Romano oriental, especialmente Alexandria e Constantinopla, continuou a comercializar com a Índia. As moedas mais tardias encontradas no subcontinente pertencem a Arcádio, Honório e finalmente a Justiniano (ver Wheller et al. 1946; Wheller 1954; Gupta 1965; Turner 1989; Sathyamurthy 1992; Cimino 1994:28-31;135-147). Uma teoria interessante, formulada por Raschke (1979), propôs a associação das moedas romanas aos monastérios budistas e ao caráter itinerante dos monges.

O rei Gautamiputra Satakarni cunhou uma moeda, nos moldes romanos, com seu perfil no anverso e um navio no reverso - símbolo das trocas marítimas que enriqueceram seu império. A existência de moeda corrente durante o período Satavahana principalmente nos reinados mais tardios - é um indício claro do crescimento econômico pelo qual passou a região em questão, cujo excedente era grande o suficiente para que o estado interviesse no controle do meio de troca (Shastri 1972; Thapar 2000).

Além das moedas, foram também escavados artefatos de cerâmica, como jarros e ânforas. A maior parte das mercadorias transportadas pelos navios cargueiros romanos era armazenada em ânforas. Os tipos de ânfora identificados no subcontinente indiano são Dressel 2-4, 6, 7 e 8. As ânforas Dressel 2-4 são associadas ao transporte de vinho e de origem romana (século I a.C - I d.C); Dressel 6 de mesma procedência, talvez para transporte de azeite; Dressel 7-8, provenientes do sul da Espanha, seriam para transporte de peixe salgado (Dressel 1879, 1899; Will 1992; Slane 1992; Cimino 1994:35-36, 154-160). As ânforas em solo indiano foram identificadas pela primeira vez na coleção cerâmica de Arikamedu (Wheller et al. 1946; Will 1992). ${ }^{5}$

Entre outros achados estão os vasos de terra sigillata, as vasilhas de vidro, as estatuetas e lamparinas de terracota, as gemas lapidadas e estatuetas de bronze. As vasilhas romanas de vidro foram encontradas em sítios como Arikamedu, Ter, Nevasa, Paithan, Kondapur, Kolhapur e Dharanikota, associadas a vasos

(5) Fragmentos de ânfora também foram relatados em Dharnikota, Nagarjunakonda e Kondapur em Andhra Pradesh; em Akota, Bet Dvarka, Devnimori, Dvarka, Hathab, Lothal, Nagara, Nani Rayan, Prabhas Patan e Shamalji, no Gujarate; Talkad em Karnataka; Ujjain, em Madhya Pradesh; Bhokardan, Brahmapuri, Junnar, Nevasa, Paunar, Sopara, Ter e Elephanta em Maharashtra; Knachipuram, Karaikadu, Kaveripattnam, Nattamedu, Vasavasamudram e Teriruveli, em Tamil Nadu; Mathurà, em Uthar Pradesh; Chandraketugarh e Tamluk em Bengala; e Taxila, no noroeste da Índia. Ver Gupta et al. (2001:7-18); Joshi e Sinha (1991); Tripathi (1993; 1995). Durante a escavação do sítio de Chaul também foram encontrados fragmentos de ânfora (Gogte e Aldrovandi, 2005-2006). Representações de ânforas podem ser observadas num relevo de Amaravati - século II d.C. e num relevo de Nagarjunakonda, do século III d.C. (Cimino 1994:XLI). 
mediterrânicos dos séculos II e I a.C., e também são recorrentes no noroeste da Índia (ver Wheller et al. 1946; Wheller 1954:173. 177; Bandinelli et al. 1965:78-84; Stern 1991). Lamparinas romanas foram encontradas em Arikamedu. No entanto, as postulações sobre alguns achados cerâmicos - como a Rouletted Ware (RW) -, considerados inicialmente de origem romana e utilizados para estabelecer a rede e a identidade dos grupos envolvidos nas trocas comerciais (ver Wheller et al. 1946) mostraram-se inconsistentes. Análises químicas demonstraram, por exemplo, que a cerâmica RW foi produzida na Índia (Gogte 1997).

A descoberta de bronzes romanos em Brahmapuri (Khandalavala 1960), Kolhapur (De Puma 1992) e uma cornucópia em Thana, evidencia a existência de um mercado de objetos de prestígio na Índia. As luxuosas peças romanas de terra sigillata foram publicadas por Wheller (1946); Comfort (1987); Slane (1992). As bullae - cópias de moedas romanas feitas em terracota ou metal na Índia, e usadas como pingentes com uma ou duas perfurações, foram encontrados em sítios do Konkan e do Deccan, como Brahmapuri, Karad, Paithan, Nevasa e Nasik. Eles também foram encontrados em sítios arqueológicos de outras regiões da Índia como Kondapur (Hyderabad), Chandravalli e Sisupalgarh (Orissa), Rajghat e Kosam (Allahabad). Esse artefato permaneceu em uso em Maharashtra até o século XVII, chamados putali (Beach 1927; Wheller 1954).

As esculturas de marfim encontradas na casa de um mercador em Pompéia, provenientes de Ter e Bhokardan, em Maharashtra, também são testemunhos das trocas comerciais entre as duas civilizações e foram discutidas por Vogel (1940), Barrett (1957-59; 1960) e Deshpande (1961); Caspers (1979); Mehendale (1991).

Nesse período, muitos yavana - provavelmente mercadores trazidos pelo aumento das trocas comerciais -, parecem ter se estabelecido em cidades indianas. As palavras yavana, yonaka ou yona, utilizadas para identificar os estrangeiros ou ocidentais, provavelmente derivaram do vocábulo yauna utilizado pelos iranianos para designar os gregos. Nas inscri- ções de Ashoka, os gregos aparecem como os yona, e essa palavra pode ter estado em uso já no século VIII a.C. (Cimino 1994:64).

No Mahabharata existe menção a uma cidade chamada Yavanapura, na costa do Konkan. O mapa Mahabharatakalina Bharatavarshaca Nakasia ${ }^{6}$ mostra essa cidade entre os atuais estados de Maharashtra e Karnataka; a cidade portuária observada logo acima é Sopara (Shurparaka), junto a Aparanta, na região de Mumbai. Assim, foi postulada a existência de um assentamento yavana de proporções consideráveis no oeste da Índia, no qual indivíduos greco-budistas foram, com o passar do tempo, indianizados e assimilados à população local, como atestam os nomes indianizados dos yavana citados nas inscrições: Dhamadhaya, Yasavadhana, Chanda. O fato de as inscrições dos yavana não mencionarem suas ocupações foi considerado um indício de que todos eles teriam uma única atividade - o comércio (ver Dehejia 1972:143; Thapar 2000:118).

Fontes textuais em Tamil confirmam a presença dos yavana ao longo da costa. Um épico chamado Silappadikaram descreve vividamente a cidade de Puhar na costa leste, perto de Pondicherry, na qual as residências dos yavana aparecem descritas como extremamente prósperas, com marujos de todas as partes da terra que viviam em comunidade (cf. Dikshitar 1939:11). Uma menção interessante presente em outro texto tamil, o Cilalladigaram [XIV. 66-67], faz uma referência específica aos yavana como guardiões do soberano no portal de Madurai, a capital do reino de Pantiyar, na qual esses estrangeiros são prezados por sua coragem. Textos literários do sul da Índia, os Sangam, datados do século I d.C., mencionam os yavana repetidamente e descrevem seus belos navios que trazem ouro e partem com pimenta do próspero porto de Muziris [Tayan Kannanar, Agam 149; 7-11]. Algumas narrativas sobre o império Satavahana no Konkan aparecem num texto sânscrito do ano 1628, o

(6) Deccan Printing Works, Pune, 1973. Ver Aldrovandi (2006:524). 
Vyadeshvar Mahatmya, associadas à descrição de um templo dedicado ao deus Shiva, próximo a Palshet, um antigo porto no litoral do Konkan, que teria sido construído no século II d.C., com a ajuda de um yavana (Paradkar 1981:79).

Como antes mencionado, existem inscrições nas grutas budistas que atestam a existência de residentes yavana em diferentes cidades do subcontinente indiano, assim como de outros, vindos de terras distantes. Nas grutas de Karli, sete yavana (Figs. 13 e 14) são mencionados entre os doadores dos pilares do caityagRha, seis deles vindos de Dhenukakata. Em Nasik, uma inscrição menciona as vitórias de Gautamiputra Satakarni sobre os Shaka, Yavana, Palhavanisudana e Ksaharata; e numa outra há menção de um yonaka Indragniddatta de Dattamitri que, com o pai e o filho, doou um caitya e três cisternas (Nagaraju 1981:41). Ainda em Nasik, há inscrições que contêm a
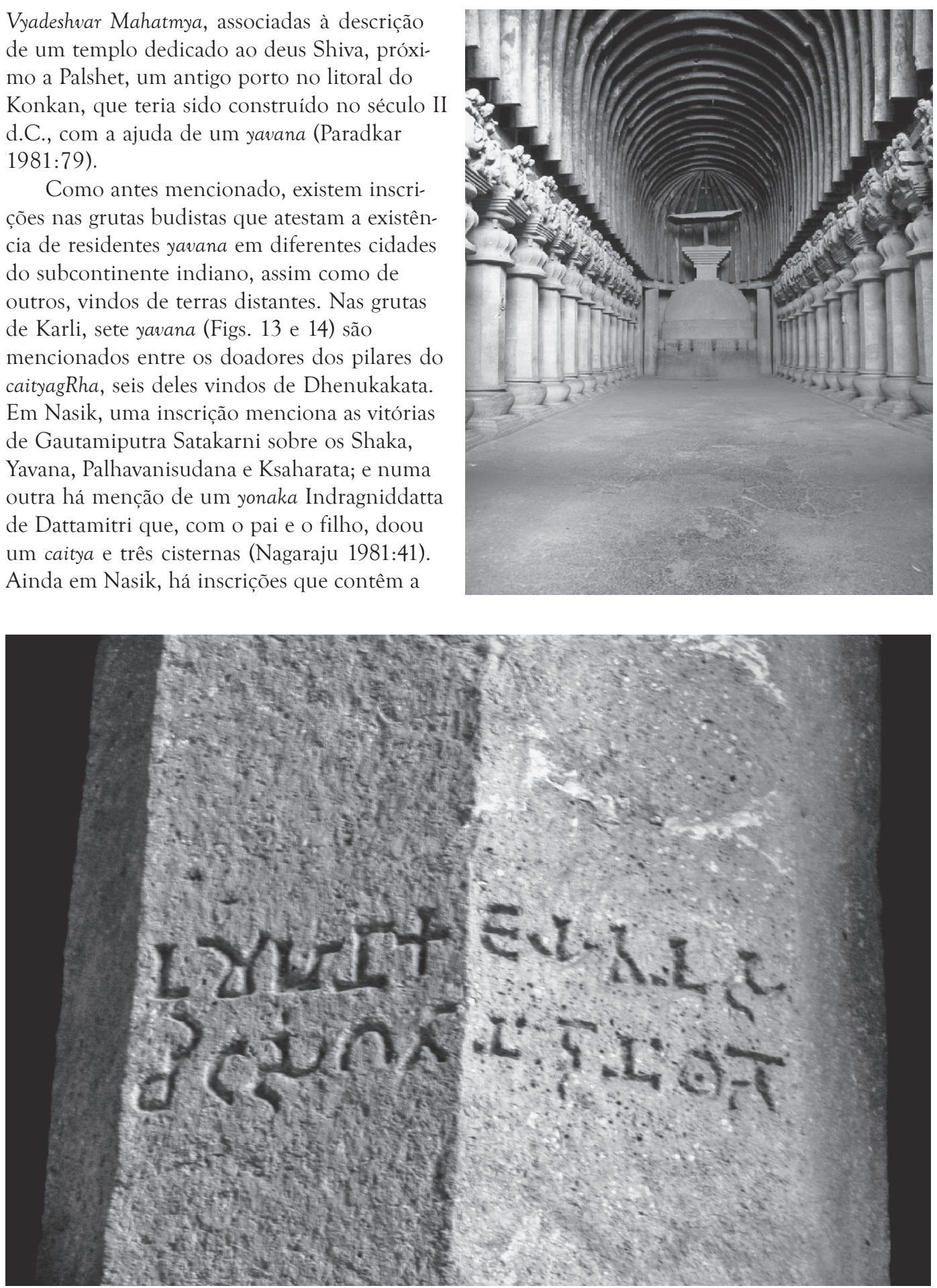

Figs. 13 e 14. A Gruta 8 do conjunto monástico de Karli, nave principal do caityagRha com o estupa na parte posterior, c. 120 d.C. Inscrição no pilar 5 da fileira direita do caityagRha, que menciona a doação do mesmo feita por um yavana chamado Vitasamgata (Aldrovandi 2004). 
palavra ramanaka, possivelmente romanaka, os romanos que dedicaram grutas aos budistas da região e inscrições em Kalyan que mencionam os yavana (Warmington 1928:112). Numa inscrição de Junnar, os yavana teriam doado duas cisternas e um refeitório, e outra menciona um yavana do país de Gata que teria doado a fachada do caityagRha. Se por um lado, as doações feitas pelos yavana funcionavam como expressões da religiosidade budista, elas também os tornavam mais próximos das guildas locais, o que poderia facilitar o comércio (cf. Thapar 2000:119).

A prosperidade econômica foi um dos principais fatores a incentivar o desenvolvimento artístico e arquitetônico no Konkan e Deccan durante o Período Histórico inicial. Nesse sentido, o afluxo de estrangeiros na região - os Shaka e yavana -, atestado pela epigrafia, poderia ter sido responsável pela incorporação de novos padrões iconográficos e arquitetônicos. No entanto, os monumentos associados ao período dos Satavahana e Ksaharata apresentaram pouca influência estrangeira. As supostas representações dos yavana atribuídas a imagens presentes em vários sítios budistas primitivos foram retratadas na forma indianizada. ${ }^{7}$

As evidências apresentadas confirmam a existência de um comércio interno e externo na região do Konkan e Deccan de caráter intenso e contínuo, capaz de criar excedentes econômicos que, aliados às mudanças políticas e religiosas ocorridas no período, foram responsáveis pelo desenvolvimento da complexa paisagem sagrada budista existente nessa área geográfica. Centenas de conjuntos de grutas talhadas na rocha aparecem junto às intersecções dessas rotas, o que reforça a evidência de uma relação bem próxima entre mercadores e a comunidade monástica budista (ver Nagaraju 1981:12; Morrison 1985:216-217).

(7) Exemplos dessas figuras podem ser observados no vihara 22 de Bhaja do século I a.C. no vihara 4 de Pitalkhorà do século I a.C., no estupa 2 de Sanci do século I a.C., no pilar do vedika do estupa de Bharhut do século II a.C., no estupa do século II d.C.de Nagarjunakonda e nos portões de Udayagiri, do século V d.C. (Huntington 1985:163,176-177).
1.5 Mercadores, nobres e monges: o budismo na região do Konkan e do Deccan

Historicamente, o desenvolvimento do Budismo esteve diretamente associado ao crescente urbanismo do Período Histórico inicial, em especial, às repúblicas, na região gangética. Por sua vez, a introdução do Budismo no Deccan e Konkan ocorreu no período Maurya, durante o reinado de Ashoka. A história do vasto conjunto de monumentos arquitetônicos talhados na rocha que é o objeto deste estudo está, portanto, diretamente associada ao desenvolvimento do Budismo nessa região.

O Mahavamsa, crônica cingalesa do século $\mathrm{V}$ d.C., menciona Tissa Moggapilutta que presidiu o terceiro concílio Budista - que teria ocorrido em Pataliputra sob os auspícios de Ashoka, 236 anos após o Nirvana do Buda -, como responsável pelo envio de missionários a várias regiões, para propagação do Dharma budista. Na lista desses locais está Aparanta, no norte do Konkan, e Maharashtra - para onde foram enviados os monges yonaka Dhammarakhita e Mahadhammarakhita, respectivamente. $\mathrm{O}$ primeiro teria convertido 37 mil pessoas após pregar o Aggikhandopamasutta - do Angutaranikaya; enquanto o segundo teria pregado o Mahakashyaharinajataka em Maharashtra (ver Dehejia 1972:143). Narrativas semelhantes aparecem no Dipavamsa, Samantapasadika, Milindapañha, Thupavamsa e Saddharmasamgraha (Nagaraju 1981:42). A historicidade do envio de missionários é corroborada por inscrições próximas a Vidisha. Relatos mais tardios como o Papañchasudani e o Saratthappakarini possuem registros lendários da passagem do Buda por Shurparaka (Sopara) na costa oeste a convite do mercador Purna que teria construído um monastério chamado Chandanasala, para marcar o local em que o Buda teria permanecido durante a visita (ver Dutt 1925:258). Entretanto, não parece haver qualquer indicação nos textos mais antigos de uma viagem do Buda pela região oeste da Índia. Apesar da impossibilidade de atestar tais narrativas, os vestígios arqueológicos e epigráficos indicam que a penetração do Budismo no oeste da Índia pode ser atribuída ao século III a.C. 
Durante o período em que chegou ao Deccan e Konkan, o Budismo já tinha passado por alguns cismas e se dividido em escolas ou ramos distintos. Sob a égide do Dharma budista encontravam-se diferentes grupos monásticos, com ideologias e práticas diferenciadas. As inscrições mais antigas, existentes nos monumentos budistas do Deccan e Konkan, não fazem referência a uma filiação budista específica. As epígrafes mais tardias, dos primeiros séculos d.C., mencionam pelo menos cinco ramos existentes na região: os Bhadrayaniya e Dharmottariya - da escola Vibhajyavadin, mais conservadora e voltada à disciplina ética e moral; e os Mahasamghika, que são citados com dois de seus ramos - os Chetika e Aparaseliya, cujo propósito estava centrado nos aspectos metafísicos e altruístas da doutrina (Nagaraju 1981:33-35).

As diferenças na ideologia e nas práticas religiosas presentes nas diferentes escolas e ramos do Budismo podem ter sido responsáveis pela variedade arquitetônica e iconográfica encontrada na região. No entanto, a pouca quantidade de inscrições que mencionam ramos budistas específicos não permite uma análise consistente desse aspecto. Apesar disso, o que parece ter ocorrido foi a convivência sincrônica de monges de diferentes ramos em alguns dos conjuntos de grutas. Esse convívio parece estar atestado por inscrições que mencionam que os monastérios eram dedicados aos monges das quatro direções catudisabhikhusamgha, ou à comunidade budista - buddhasamgha, encontradas em Kanheri, Karli e Nasik (Nagaraju 1981:43).

Como observado por Dutt (1925:291), o relato de Hiuen Thsiang, embora mais tardio, menciona que, durante o século VII d.C., mestres de diferentes escolas viviam num mesmo monastério. Assim, é possível que a ênfase nas diferenças entre os diversos ramos budistas, mencionadas nas crônicas páli, tenham sido acréscimos posteriores. A arquitetura religiosa mais tardia do início do período Medieval, indica uma paisagem diversificada e a coexistência de centros monásticos budistas, heremitérios e templos bramânicos, além de outros cultos regionais (ver Ray 2006). A convivência dos monges budistas com membros de outras religiões como o Bramanismo e o Jainismo também é um aspecto extremamente importante para compreensão da interação religiosa ocorrida nessa região, no entanto esta análise foge ao escopo do presente artigo. ${ }^{8}$

Os conjuntos de grutas budistas foram criados com a finalidade de abrigar os monges, portanto seu padrão arquitetônico esteve intrinsecamente associado às práticas e necessidades da vida monástica de cada período. Alguns aspectos da ordem monástica budista podem ser traçados a partir dos Vinaya, no entanto, essas fontes receberam acréscimos posteriores com o objetivo de adaptar as necessidades da comunidade à realidade dos períodos sucessivos de desenvolvimento dessa religião. Com o crescimento da Ordem budista e a admissão de discípulos leigos, as necessidades do samgha se modificaram.

As fontes canônicas atribuem o início da doação de monastérios ao período final da vida do Buda. Os monges, que no Budismo primitivo eram itinerantes, se encontravam nesses conjuntos de grutas durante os retiros realizados na estação chuvosa. De acordo com o Mahavamsa [XVI. 2; XVII.1] tal prática recebia o nome de vassAvAsa que era iniciada no $13^{\circ}$ dia da lua crescente de Asadha e terminava na lua cheia do mês de Karttika. No início as habitações monásticas teriam sido celas ou cabanas, individuais - e a ênfase esteve voltada ao isolamento ascético. No restante do ano, de acordo com prescrições do Vinaya, os monges não deveriam permanecer num mesmo lugar por mais de três dias (ver Dutt 1925:101). Com o passar do tempo, esses mendicantes budistas passaram a coexistir por períodos mais prolongados e administrar esses centros monásticos. Os monastérios sazonais, fossem

(8) Como lembraram Trautmann e Sinopoli (2002:500), a definição de períodos históricos a partir de elementos arquitetônicos provenientes das religiões budista, hinduísta e muçulmana foi uma grande e perigosa simplificação, que continua a existir atualmente no Sul da Ásia. Ao atribuir primazia à identidade religiosa como a variável mais importante na história dessa região, negou-se a complexidade histórica que envolve a paisagem religiosa, étnica, política e social do Sul da Ásia. 
eles edifícios de tijolo ou construções talhadas na rocha, passaram a ter um caráter permanente (Basham 1951:151-152).

Os estudos, realizados ao longo do século $\mathrm{XX}$, sobre as comunidades do Budismo primitivo no sul da Ásia deram ênfase ao suposto isolamento intencional dos centros monásticos: os locais estariam próximos o suficiente para permitir que os monges pudessem receber doações diárias de alimento da população leiga, mas distantes o bastante para permitir um afastamento favorável ao caráter contemplativo do Budismo.

Embora esse distanciamento possa ter existido nas épocas mais remotas, há indicações do caráter ambíguo dessa teoria quando confrontada com os monastérios surgidos a partir do século I a.C. Não há dúvida de que, no caso da paisagem sagrada elaborada no Deccan e Konkan, as grutas talhadas na rocha estiveram situadas em locais que, até certo ponto, estavam afastados dos centros urbanos, geralmente com vista privilegiada do vale e das cercanias. No entanto, a clara associação desses conjuntos monásticos com as rotas comerciais que interligavam a região requer uma reflexão sobre o grau de isolamento intencional supostamente engendrado pelas comunidades monásticas.

A distribuição espacial dessa paisagem sagrada é um indicador visivelmente diferenciado, senão mesmo antagônico, daquele proposto por teorias baseadas na necessidade de isolamento físico. Nesse sentido, o isolamento pode não ter sido tão fundamental quanto se acreditou ou, ainda, pode ter possuído finalidades mais abrangentes ou distintas daquelas inicialmente propostas, como, quiçá, a segurança e proteção. A escolha dos locais onde seriam construídos os conjuntos monásticos foi sem dúvida alguma intencional, entretanto, não se pode desconsiderar as evidências que apontam para as mudanças nos propósitos que envolveram a localização dos centros religiosos. Estudos mais recentes verificaram, por exemplo, que a partir de um determinado período os monastérios passaram a acumular somas consideráveis de dinheiro, decorrentes de contratos e empréstimos a juros feitos a partir das doações à comunidade budista (ver Kosambi 1955:59-60; Schopen 1997; 2004). Esse fato, por si só, já exigia uma segurança maior do local.

Enquanto as teorias mais antigas sobre a função desses monastérios enfatizaram o isolamento intencional e o papel da nobreza no financiamento dos centros monásticos (Cunningham 1854; Fergusson e Burguess 1880; Sastri 1966; Nagaraju 1981), existiram visões que atribuíram mais autonomia aos monastérios e monges (Brown 1941) e, mais recentemente, voltadas justamente à ênfase na localização dos complexos monásticos ao longo das rotas comerciais e seu envolvimento com o comércio de longa distância e a produção agrícola (Thapar 1966; Dehejia 1972; Heitzman 1984; Ray 1986; Lahiri 1992; e Morrison 1995).

Essa aparente incoerência entre as formulações canônicas e a prática efetiva das comunidades budistas do Deccan e Konkan remete a aspectos extremamente importantes para compreensão da interação do Budismo primitivo com as demais esferas da sociedade na Índia antiga. Muito do que de se definiu sobre os primórdios do Budismo pautou-se nas fontes escritas - os cânones budistas - e relegou as fontes arqueológicas ao segundo plano.

O pioneirismo de Schopen $(1997 ; 2004)$ e de outros estudiosos contribuiu para o surgimento de novas perspectivas sobre os primórdios do Budismo que discutiram extensamente essas questões. Essas abordagens com ênfase na prática religiosa baseiam-se exatamente na recuperação e equiparação dos dados arqueológicos e epigráficos, que são confrontados com a suposta verdade apresentada pelo discurso budista preservado nas fontes textuais. Nesse sentido, a realidade material vem trazendo uma nova luz aos estudos budológicos e tem revelado um perfil monástico e laico muito mais pragmático e dinâmico que aquele idealizado nos princípios sagrados e nos discursos filosóficos presentes nos textos canônicos. Ser budista não era um mero exercício do intelecto, mas também incorporava práticas rituais - peregrinação, circum- 
ambulação, doações -, que podem ser recuperados a partir dos vestígios e contextos arqueológicos.

Nesse sentido, a idéia de isolamento intencional merece ser revista sob a ótica de um engajamento religioso surgido durante o desenvolvimento do Budismo primitivo e da retórica da paisagem sagrada a ele associada. Os conceitos de engajamento econômico e engajamento religioso fornecem interpretações inovadoras a respeito da relação entre os monges e a comunidade leiga.

A maior parte dos conjuntos monásticos talhados na rocha, no Deccan e Konkan, possui um caityagRha com um estupa tridimensional ou em baixo-relevo. A presença desses elementos denota uma ênfase no aspecto devocional budista, uma vez que a adoração do estupa esteve associada ao culto das relíquias do Buda. Por outro lado, o caráter monacal desses conjuntos arquitetônicos não excluía a presença da população leiga, mas promovia a interação entre as duas comunidades. Um bom exemplo dessa relação foi verificado na arquitetura do monastério de Thotlakonda, na costa leste da Índia, que evidenciou a necessidade de um engajamento ritual fruto da interação entre as duas comunidades. No entanto, as idiossincrasias de cada grupo teriam gerado, de lado a lado, tensões e resistências que permaneceram observáveis na distribuição espacial dessa arquitetura monástica (cf. Fogelin 2003).

A interação contínua entre os monges e a população leiga teria sido responsável pelo desenvolvimento de uma atmosfera piedosa, que resultou no crescimento das doações feitas por essa última - o que, por outro lado, revertia em méritos (Nagaraju 1981:36). Esses méritos, de acordo com os cânones budistas, podiam ser alcançados por meio da doação de acomodações, alimentos e vestes à comunidade monástica.

Assim, a construção da paisagem sagrada budista do Deccan e Konkan esteve diretamente associada ao anseio leigo e monástico de obter méritos espirituais - punya. Como vimos, grande parte das inscrições presentes nos conjuntos de grutas atesta as doações de diferentes camadas sociais ao bhikusamgha - a comunidade monástica. A análise do material epigráfico associado ao patrocínio e à construção dos monumentos budistas revelou que diferentes camadas sociais financiaram a criação desses estabelecimentos monásticos. Os comerciantes - entre eles os yavana -, formam o grupo que se destaca como principal doador dos conjuntos de grutas, seguidos pelos nobres, oficiais, clérigos e, em menor número, agricultores e artesãos (Dehejia 1972:45-70). Um levantamento sistemático e a quantificação das inscrições em cerca de 40 conjuntos de grutas somou 156 registros com menção ao doador, dentre estes: 35\% foram feitos por mercadores; $23 \%$ pela nobreza; seguidos pelos oficiais e clérigos, com $12 \%$ cada; e agricultores e artesãos com 10\%; os yavana são mencionados em 10 inscrições, que representam 8\% do total (Nagaraju 1981:2729, 328-364).

O desenvolvimento de uma arquitetura mais complexa, através dos tempos, esteve também associado ao crescimento de doações permanentes, que incluíram somas em dinheiro ou, ainda, terras cultiváveis. Embora os cânones budistas mencionem uma regra que teria sido determinada pelo próprio Buda sobre a não aceitação de terras, animais e dinheiro (Beal 1883 [XXVI.2020]; Johnston 1936 [XXVI.27]), como vimos, a epigrafia aponta para a existência de um excedente econômico proveniente das doações de terras cultivadas, que era dividido entre a comunidade monástica. Esses monastérios eram consumidores dos bens de que faziam uso e, embora não existam informações conclusivas a esse respeito, talvez também sediassem atividades de trocas ou possuíssem mercados nas cercanias (Dehejia 1972:144-145; Ray 2006:83). O antigo vilarejo de Mahad, associado ao conjunto monástico de mesmo nome, foi um grande mercado de acordo com o significado local atribuído a esse vocábulo na antiguidade (Aldrovandi 2006:544).

Ao mesmo tempo, os cânones budistas registraram que uma das primeiras regras estabelecidas pelo Buda era a subsistência do monge com alimento obtido por meio da 
mendicância. Nos primórdios do Budismo, os monges deviam ir até o vilarejo ou cidade mais próxima para receber doações de alimento mesmo durante os meses de retiro (ver Dutt 1925:70, 173; Morrison 1995:216). No entanto, alguns elementos arquitetônicos deixam claras as mudanças dessa prática religiosa, como a inclusão, por exemplo, dos refeitórios - maTapa -, nesses conjuntos. Outro elemento indicativo de mudança foi a construção de locais para hospedar a população leiga de passagem pelos monastérios, como os mercadores que percorriam as rotas comerciais próximas. Ajuda prestada por monges aos mercadores é um fato histórico bem conhecido e incluía desde abrigo para repouso na travessia das rotas comerciais até, como vimos, o empréstimo de dinheiro a juros.

\subsection{Considerações sobre a retórica da paisa- gem budista na costa oeste da Índia antiga}

Assim como nas esferas política e econômica, as mudanças sociais e religiosas ocorridas durante o período Histórico Inicial no Deccan e Konkan foram geralmente atribuídas a agentes externos, fossem eles, as unidades sociopolíticas Maurya ou a intervenção econômica estrangeira (Morrison 1995; Ray 2006). No entanto, as evidências arqueológicas acentuam o caráter multidimensional da estrutura religiosa e do papel que ela exercia na negociação entre os diferentes grupos sociais.

A esfera religiosa funcionava em níveis múltiplos e interagia com diferentes grupos de modos variados. Nesse sentido, a retórica da paisagem sagrada fornecia ancoragem e meios de fortalecer a identidade social das comunidades que interagiam nessas regiões. $O$ papel da arquitetura religiosa, mais que um simples registro da ocupação espacial dos agentes de legitimação política reivindicada por diferentes setores dessa sociedade, deve ser compreendido como um instrumento retórico de persuasão, impresso na paisagem, a influir diretamente na dinâmica que integrava indivíduos e comunidades no tecido social.

Ao mesmo tempo, se a construção de novos monastérios estimulava o crescimento econômico, o uso dessa retórica arquitetônica transformava a paisagem geográfica e social da região. As grutas budistas eram parte preponderante da paisagem sagrada e, por sua vez, exerciam um papel fundamental na esfera laica. Os centros monásticos budistas recebiam donativos e provisões não apenas dos reis e governantes em busca de poder e prestígio, mas das demais camadas sociais. A persistência ao longo do tempo ocorreu graças a sua habilidade de criar relações socioeconômicas com uma variedade mais ampla de comunidades e favorecer sua coexistência.

Como vimos, as atividades comerciais, por sua própria natureza, possuíam um caráter dinâmico que atravessava as fronteiras políticas e, como resultado, criava suas próprias redes de comunicação e transferência de informação. Dentro desse sistema extenso de trocas, as diversas comunidades participantes desenvolveram identidades culturais distintas ao interagir com seu ambiente regional (cf. Ray 2006:68), bem como com a esfera cultural indiana mais ampla e mesmo estrangeira.

Essas identidades sociais, por sua vez, incluíam afiliações religiosas. Diferente do Bramanismo, o Budismo, por questões filosóficas e sociais, como por exemplo a ausência de impedimentos baseados no sistema de castas e nos tabus religiosos, esteve mais aberto ao comércio de longa distância. Isso o tornava mais abrangente, pois possibilitava uma ampla participação de diferentes setores da sociedade, com castas distintas, ou mesmo sem casta estrangeiros -, em um mesmo sistema.

O Budismo forneceu, nesse sentido, uma ideologia mais atraente e, ao mesmo tempo, um meio de legitimação de grupos da sociedade que antes não possuíam acesso a posições de poder e prestígio. Como indica o registro epigráfico, apesar da aparente equanimidade preconizada pela filosofia budista, na prática as doações preservavam a diferença de status entre os doadores (Thapar 1984; Morrison 1995; Ray 2003).

As instituições budistas formavam um elemento unificador das ações políticas e as doações provenientes do desenvolvimento econômico permitiam que as diferentes camadas sociais expressassem e reafirmassem 
sua posição e status (Heitzman 1984:132).

Esses monastérios distribuídos na paisagem sagrada se tornavam centros de lealdade ao estado (Thapar 2000:117), o que era particularmente importante em regiões de fronteira pelas quais as rotas comerciais passavam. A multiplicidade de papéis dos monastérios favorecia a inter-relação entre o estado, a economia e as instituições religiosas.

Como pudemos verificar, essa paisagem sagrada de caráter preponderantemente retórico surgiu paralelamente ao desenvolvimento das esferas política, econômica e religiosa da época e se desenvolveu graças à sua capacidade de criar espaço para a interação de um meio humano extremamente diversificado. A sociedade heterogênea do Sul da Ásia no período Histórico Inicial incorporava afiliações de diferentes sistemas de crenças. Nesse sentido, os estudos arqueológicos e históricos dessa paisagem sagrada ajudam a localizar essas redes discursivas mais amplas ao longo do tempo e espaço que, por sua vez, contribuem para a compreensão de questões relativas às estruturas da sociedade e as formas como as comunidades do passado construíram suas identidades sociais.

\section{Agradecimentos}

Ao Prof. Vishwas D. Gogte, professores e colegas do Deccan College Post-Graduate and Research Institute, Pune, Índia, pelo apoio ao desenvolvimento desta pesquisa. À Profa. Elaine F.V. Hirata e ao LABECA-MAE. À FAPESP pelo financiamento do estágio naquele Instituto.

ALDROVANDI, C.E.V. Secular routes and rock-cut monasteries: rhetoric of Buddhist sacred landscape in the west coast of ancient India. Revista do Museu de Arqueologia e Etnologia, São Paulo, 17: 39-67, 2007.

Abstract: Based on the field survey undertook during 2004 and 2005, this article discusses the development and interaction of the Buddhist sacred landscape from Deccan and Konkan regions. Hundreds of rock-cut caves developed along the ancient commercial routes which linked the west coast of Maharashtra state, they work as spatial marks in the landscape making it possible to establish ways of access from the coast to the platô. The continuous growth and recurrence of these monasteries along almost one milenia are considered under the perspective of the sacred landscape's rhetoric. This approach allows understanding the interaction and the dynamics among political, economic and religious spheres in this geographic area of ancient India.

Keywords: Landscape's rethoric - Buddhist caves - Politics - Economy Ancient India.

\section{Referências bibliográficas}

ABBOTT, J. E.

1981 Recently discovered Buddhist caves at Nadsur and Nenavli in the Bhor state, Bombay Presidency. Indian Antiquary, XX: $120-9$.
ALDROVANDI, C.E.V.

2006 As exéquias do Buda Sakyamuni: morte, lamento e transcendência na iconografia indiano-budista de Gandhara. Tese de Doutorado. Museu de Arqueologia e 
Etnologia, Universidade de São Paulo, São Paulo.

ALLCHIN, B.; ALLCHIN, R.

[1982] $1996 \quad$ The Rise of Civilization in India and Pakistan. Cambridge: University Press.

BANDINELLI, R. B.; EGGERS, H.J.; COARELLI, F.

1965 Arte romana e commercio artistico oltre $i$ confini. Istituto della Enciclopédia Italiana, vol. VI. Roma: Istituto Poligrafico dello Stato, P.V.

BARRETT, D.

1957-59 Ancient Indian Ivories. Bulletin of the Prince of Wales Museum of Western India, 6: 4-63.

1960 Ter. The Heritage of Indian Art, Bombay, 5: 8-19.

BASHAM, A.L.

1951 History and Doctrines of the Ajivikas: a Vanished Indian Religion. London: Luzac and Co.

BEACH, H.C.

1927 Classification and Nomenclature of Beads and Pendants. Archaeologia, LXXXVII: 27-39.

BEAL, S. (TRAD.)

[1883] 1998 The Fo-Sho-Hing-Tsan-King: A Life of Buddha by Asvaghosha Bodhisattva. Translated from the Sanskrit to Chinese by Dharmaraksha, A.D. 420. Müller, F.M. (Ed.) Sacred Books of the East, v.19. Delhi: Motilal Banarsidas.

BEGLEY, V.; DE PUMA, R.D. (EDS.)

1992 Rome and India: the Ancient Sea Trade. Delhi: Oxford University Press.

BROWN, P.

1941 Indian Architecture: the Buddhist and Hindu Period. Bombay: D.B. Taraporevala Sons and Co.

BURGESS, J.

1883 Reports on the Buddhist Cave Temples and their inscriptions. Archaeological Survey of Western India Publication Series IV, London.

CASPERS, E.C.L.D.

1979 The Indian Ivory Figurine from Pompeii; a Reconsideration of its Functional Use. South Asian Archaeology: 341-53.

CASSON, L.

1986 Ship and Seamanship in Ancient World. Princeton: University Press.

CHAKRABARTI, D.K.

1995 Buddhist sites across South Asia as influenced by political and economic forces. In: Barnes, G. (Ed.) Buddhist Archaeology, World Archaeology, 27 (2): 185-202.

CHANDRA, M.

1977 Trade and Trade Routes in Ancient India. New Delhi: Abhinav Publications.

CHARPENTIER, J.

1927 Surparaka. Journal of the Royal Asiatic Society: 111-25.

CIMINO, R.M. (ED.)

1994 Ancient Rome and India: commercial and cultural contacts between the Roman World and India. Istituto Italiano per il Medio ed Estremo Oriente, Rome. New Delhi: Munshiram Manoharlal Pub. Pvt. Ltd.

COMFORT, H.

1987 Terra sigillata from Arikamedu. American Journal of Archaeology, 91: 292-9.

COOMARASWAMY, A.K.

1965 History of Indian and Indonesian Art. London: Dover Publications.

CUNNINGHAM, SIR A.

[1854] $1966 \quad$ Buddhist Monuments of Central India. London, Varanasi.

DEHEJIA, V.

1972 Early Buddhist Rock Temples: a Chronological Study. London: Thames and Hudson.

DE PUMA, R.D.

1992 The Roman Bronzes from Kolhapur. In: Begley, V.; De Puma, R.D. (Eds.) Rome and India: the Ancient Sea Trade. Delhi, Oxford University Press: 82-112.

DESHPANDE, M.N.

1959 The rock-cut caves of Pitalkora in the Deccan. Ancient India, 15: 66-93.

1961 Some Observations on the Ivory Figure from Ter. Lalit Kala, 10: 55-6.

DIKSHITAR, V.R.R.

1939 The Silappadikaram. Oxford: University Press. DRESSEL, $\mathrm{H}$.

1879 Di un grande deposito di anfore rinvenute nel nuovo quartiere del castro pretorio. Bullettino Comunale, 7: 36-112; 143-96.

1899 Corpus Inscriptionum Latinarum, XV. Berlin.

DUNCAN, J.S.

1990 The City as Text: the Politics of Landscape Interpretation in the Kandyan Kingdom. Cambridge: University Press.

DUTT, N.

[1925] $2005 \quad$ Early History of the Spread of Buddhism and the Buddhist Schools. New Delhi: Cosmo. 
DUTTA, M.

1990 A Study of Satavahana Coinage. New Delhi: Harman Pub. House.

FERGUSSON, J.; BURGESS. J.

[1880] 1969 The Cave Temples of India. New Delhi: Oriental Books Reprint Corporation.

FILLIOZAT, J.

1949 Les échanges de l'Inde et de l'Empire romain, au premièrs siècles de l'ère chrétienne. Revue Historique, 201: 5-6.

FOGELIN, L.E.

2003 Beyond the Monastery Walls: the Archaeology of Early Buddhism in North Coastal Andhra Pradesh, India. PhD Thesis. UMI Microform, Ann Harbor, Michigan.

GOGTE, V.D.

1997 Chandraketugarh - Tamluk Region of Bengal: Source of the Early Historic Rouletted Ware from India and Southeast Asia. Man and Environment, XXII: 69-85.

GOGTE, V.D.; ALDROVANDI, C.E.V.

2005-06 A Simylla do Périplo do Mar Eritreu: Escavação Arqueológica do Antigo Sítio Portuário de Chaul, na costa oeste de Mahàràùñra - Índia. Revista do Museu de Arqueologia e Etnologia, São Paulo, 15-16: 247-269.

GOKHALE, S.

1999 Satavahana Coinage: origins and influences. In: Shastri, A.M. (Ed.) The Age of Satavahanas. New Delhi, Aryan Books International: 278-86.

GUPTA, P.L.

1965 Roman Coins from Andhra Pradesh. Hyderabad: Government of Andhra Pradesh.

GUPTA, S.; WILLIAMS, D.; PEACOCK, D.

2001 Dressel 2-4 Amphorae and Roman Trade with India: the evidence at Nevassa. Journal of South Asian Studies, 17: 7-18.

HEITZMAN, J.

1984 Early Buddhism: trade and empire. In: Kennedy, K.A.R.; Possehl, G.L. (Eds.) Studies in the Archaeology and Paleoanthropology of South Asia. New Delhi, Oxford University Press: 121-38.

HUNTINGFORD, G.W.B.

1980 The Periplus of Erythraean Sea. London: The Hakluyt Society.

HUNTINGTON, S.L.

1985 The Art of Ancient India, with contributions by John C. Huntington. New York: Weather Hill, n.ed. 1993.
JOHNSTON, E.H.

1936 Asvaghosa's Buddhacarita or Acts of the Buddha. Lahore. Delhi: Motilal Banarsidass (2004).

1941 Two notes on Ptolomy's Geography of India. Journal of the Royal Asiatic Society: 208-17.

JOSHI, M.C.; SINHA, A.K.

1991 Discovery of an Amphora Handle from Mathura. In: Margabandhu, C. et al. (Eds.) Indian Archaeological Heritage: 255 9.

KHANDALAWALA, K.J.

1970 Brahmapuri: a consideration of the metal objects found in the Kundangar Hoard. Lalit Kala, 7: 29-75.

KOSAMBI, D.D.

1955 Dhenukakata. Journal of the Asiatic Society of Bombay, 30: 51-63.

1976 The Culture and Civilization of Ancient India in Historical Outline. New Delhi: Vikas Publishing House.

LAHIRI, N.

1992 The Archaeology of Indian Trade Routes (up to c.200 B.C.). Delhi: Oxford Univesrity Press.

LÜDERS, H.

1912 A List of Brahmi Inscriptions from the earliest times to A.D. 400 with the exception of those of Asoka. Epigraphia Indica, X, Appendix.

MAJUMDAR, R.C.; PUSALKAR, A.D. (EDS.)

1953 The Age of Imperial Unit. Bombay: Bharatiya Vidya Bhawan.

MEHENDALE, S.

1991 The Ivory Statuette from Bhokardan and its Connection to the Ivory Statuettes from Pompeii and Ter. South Asian Archaeology: 529-38.

MIRASHI, V.V.

1955 Inscriptions of Satavahanas and the Western Kshatrapas, Corpus Inscriptionum Indicarum IV, part I, A.S.I. Delhi: Aryan Books International.

MORRISON, K.

1995 Trade, urbanism and agricultural expansion: Buddhist monastic institutions and the state in early historic western Deccan. In: Barnes, G. (Ed.) Buddhist Archaeology, World Archaeology, 27 (2): 203-21.

NAGARAJU, S.

1981 Buddhist Architecture of Western India (c.250 B.C. c. A.D.300). Delhi: Agam Kala Prakashan. 
NILAKANTA SASTRI, K.A.

1957 A Comprehensive History of India, vol. II, The Mauryas and Sartavahanas 325 B.C. - A.D. 300. Bombay: Orient Longmans.

1966 A History of South India: from Pre-Historic Times to the Fall of Vijayanagar. Delhi, Oxford University Press.

PARADKAR, M.D.

1981 Vyadeshwat Mahatmya. Bombay: KeshavBhikaji Dhavale Pub.

PARASHER-SEN, A. (ED.)

1993 Culture and Civilization: the beginnings. In: Social and Economis History of the Early Deccan: Some Interpretations. Delhi: Manohar, 1993:66-114.

RASCHKE, M.G.

1979 The Role of Oriental Commerce in the Economies of the Cities of the Eastern Mediterranean in Roman Period. Archaeological News, 8: 68-77.

RAY, H.P.

1985 Trade in the West Deccan under the Satavahanas. Studies in History, 1 (1):15-35.

1986 Monastery and Guild: Commerce under the Satavahanas. Delhi: Oxford University Press.

1988 Yavana presence in Ancient India. Journal of the Economic and Social History of the Orient, Leiden, 31: 311-25.

2003 The Archaeology of Seafaring in Ancient South Asia. Cambridge: University Press.

2006 The Archaeology of Bengal: trading networks, cultural identities. Journal of Economic and Social History of the Orient. Koninklikje Brill NV, Leiden: 68-95.

SANKALIA, H.D.

1974 The Pre-History and Proto-History of India and Pakistan. Poona: Deccan College PostGraduate and Research Institute.

SANKALIA, H.D.; DIKSHIT, M.G.

1952 Excavations at Brahmapuri (Kolhapur) 1945-46. Poona: Deccan College PostGraduate and Research Institute.

SANKALIA, H.D.; DEO, S.B.

1955 Reports on the Excavations at Nasik and Jorwe 1950-51. Poona: Deccan College Post-Graduate and Research Institute.

SANKALIA, H.D.; DEO, S.B.; ANSARI, Z.D.; EHRHARDT, S.

1960 From History to Pre-History at Nevasa (1954. 56). Pune: Deccan College.

SARMA, I.K.

1980 Coinage of the Satavahana Empire. Delhi: Agam.
SATHYAMURTHY, T.

1992 Catalogue of Roman Gold Coins. Thiruvananthapuram, Kerala.

SCHOPEN, G.

1997 Bones, Stones and Buddhist Monks. Collected Papers on the Archaeological, Epigraphy and Texts of Monastic Buddhism in India. Honolulu: University of Hawai Press.

2004 Buddhist Monks and Business Matters: Still More Papers on Monastic Buddhism in India. Honolulu: University of Hawai Press.

SENART, É.

1903 Inscriptions of the caves at Karle. Epigraphia Indica, VII: 47-56.

SHASTRI, A.M. (ED.)

1972 Coinage of the Satavahanas and Coins from Excavations. Nagpur: University Press.

1987 Early History of the Deccan: Problems and Perspectives. Delhi: Sundeep Prakashan.

SINOPOLI, C.M.

2001 On the Edge of Empire: Form and Substance in the Satavahana Dynasty. In: Alcock, S.; Daltroy, T.N.; Morrison, K.D.; Sinopoli, C.M. (Eds.) Empire: Perspectives from Archaeology and History. Cambridge, University Press: 155-78.

SLANE, K.W.

1992 Observations on Mediterranean Amphoras and Tablewares found in India. In: Begley, V.; De Puma, R.D. (Eds.) Rome and India: the Ancient Sea Trade. Delhi, Oxford University Press: 204-215.

STERN, E.M.

1991 Early Roman Export Glas in India. In: Begley, V.; De Puma, R.D. (Eds.) Rome and India: the Ancient Sea Trade. Madison, University of Wisconsin Press: 157-196.

THAPAR, R.

1966 A History of India. London: Penguin Books.

1984 From Lineage to State. Bombay: Oxfrod University Press.

2000 Regional History with Reference to the Konkan. In: Cultural Pasts: Essays in Early Indian History. Oxford, University Press: 107-122.

THOSAR, H.S.

1991 Dhenukakata, the Earliest Metropolis of the Deccan with a Yavana Settlement. In: Arora, U.P. (Ed.) Graeco-Indica: India's Cultural Contacts with the Greek World. New Delhi, Ramanand Vidya Bhavan: 172-7. 
TRAUTMANN, T.R.; SINOPOLI, C.M.

2002 In the Beginning was the Word: Escavating the Relations between History and Archaeology in South Asia. Journal of Economic and Social History of the Orient. Koninklikje Brill NV, Leiden: 492-523.

TRIPATHI, A.

1993 Amphorae from Elephanta Island: Fresh Evidence of Westerly Trade. Yavanika, 3, Journal of the Indian Society for Greek and Roman Studies: 67-74.

1995 A Roman Amphora from Lothal. Indian Society for Greek and Roman Studies: 92-9.

TURNER, P.J.

1989 Roman Coins from India. London: Royal Numismatic Society, n. 22.

VOGEL, J.P.

1940 Note on an Ivory Statuette from Pompeii. Annual Bibliography of Indian Archaeology, XIII: 1-5.
WARMINGTON, E.H.

[1928] 1995 The Commerce Between the Roman Empire and India. New Delhi, Munshiram Manoharlal Pub. Pvt. Ltd.

WHEELER, R.E.M.

1954 Rome Beyond Imperial Frontiers. London: G. Bell and Sons Ltd.

WHEELER, R.E.M.; GOSH, A.; DEVA, K.

1946 Arikamedu: an Indo-Roman Trading Station on the East Coast of India. Ancient India, 2: 17-124.

WILL, E.L.

1992 The Mediterranean Shiping Amphoras from Arikamedu. In: Begley, V.; De Puma, R.D. (Eds.) Rome and India: the Ancient Sea Trade. Delhi: Oxford University Press: 151-6.

YAZDANI, G.

1960 The Early History of Deccan. 2 vols., London: Oxford University Press. 